\title{
Northern Hemisphere Rossby Wave Initiation Events on the Extratropical Jet-A Climatological Analysis ${ }^{\mathscr{O}}$
}

\author{
MATTHIAS RÖTHLISBERGER \\ Institute of Geography, and Oeschger Centre for Climate Change Research, University of Bern, Bern, Switzerland \\ OLIVIA MARTIUS \\ Institute of Geography, and Oeschger Centre for Climate Change Research, and Mobiliar Laboratory for Natural Risks, \\ University of Bern, Bern, Switzerland \\ HEINI WERNLI \\ Institute for Atmospheric and Climate Science, ETH Zürich, Zürich, Switzerland
}

(Manuscript received 24 May 2017, in final form 15 September 2017)

\begin{abstract}
A climatology of Rossby wave initiation (RWI) events on the Northern Hemisphere midlatitude jet is compiled by applying an objective RWI identification algorithm to the ERA-Interim dataset. In winter, RWI events occur most frequently over the northwestern Pacific and less often over the North Atlantic. In summer, the total number of RWI events is lower than in winter and the North Pacific RWI region shifts toward the Tibetan Plateau. Composite analysis of the large-scale flow prior to, during, and after winter North Pacific RWI events shows an upstream wave train propagating across Asia on the Arctic waveguide prior to RWI. The composite wave forms on a relatively weak zonal jet streak, exhibits a baroclinic structure, and is strongly amplified by latent heat release in the warm conveyor belt of a deepening surface cyclone. Moreover, the wave forms in a region of large-scale upper-level deformation, upstream of a preexisting ridge. Further, active tropical convection affects the longitude where RWI occurs and thus acts as a geographical anchor for RWI. Individual RWI events are characterized by preferred combinations of these composite features: a strong surface cyclone tends to occur in concert with strong latent heating and a pronounced positive PV anomaly aloft. A second group of co-occurring features contains active tropical convection, a strengthened subtropical anticyclone, and the downstream ridge. These feature groups might be regarded as idealized archetypal RWI scenarios, although numerous intermediate events exist where features from both groups occur together.
\end{abstract}

\section{Introduction}

Synoptic-scale Rossby waves are the most prominent large-scale midlatitude flow features in the tropopause region. They manifest themselves as trough and ridge patterns with a wavelength of $4000-5000 \mathrm{~km}$ (Chang and $\mathrm{Yu}$ 1999), which propagate along midlatitude jets (Hoskins and Ambrizzi 1993; Martius et al. 2010). While doing so, they are organized in wave packets (Chang

\footnotetext{
Supplemental information related to this paper is available at the Journals Online website: http://dx.doi.org/10.1175/JCLI-D-170346.s1.
}

Corresponding author: Matthias Röthlisberger, matthias. roethlisberger@giub.unibe.ch
1993; Lee and Held 1993), which populate the storm tracks and modulate surface weather by steering and interacting with surface cyclones and anticyclones. Wave packets have a zonal group velocity of $15-30 \mathrm{~m} \mathrm{~s}^{-1}$ (Chang and Yu 1999; Hakim 2003; Souders et al. 2014), which exceeds the phase velocity of the individual wave crests (5-10 $\mathrm{m} \mathrm{s}^{-1}$; Chang and Yu 1999; Hakim 2003), and therefore exhibit downstream development.

In a potential vorticity (PV) perspective, Rossby waves can be viewed as tropopause-level PV anomalies propagating along regions of enhanced isentropic PV gradients (i.e., jet streams), which act as waveguides (Hoskins et al. 1985; Hoskins and Ambrizzi 1993; Schwierz et al. 2004; Martius et al. 2010). Here we make use of the PV perspective to study the initiation of synoptic-scale Rossby waves. We define Rossby wave 
initiation (RWI) as events where an initially zonal and straight jet stream segment is perturbed from either its stratospheric or tropospheric side and starts to undulate for other reasons than downstream development. Hence, RWI is understood as the formation of the first wave crest of a Rossby wave packet and, therefore, the presence of a zonal and straight jet is a prerequisite for RWI. Here we extend the work of Röthlisberger et al. (2016), who introduced this RWI concept to develop an automated RWI identification algorithm. We first compile and discuss the all-season climatology of RWI events occurring on the Northern Hemisphere extratropical jet. Thereafter, this climatology is used to explore the evolution of composite RWI events in order to draw inferences on the different mechanisms leading to RWI.

In the isentropic view of the upper-level flow employed here, RWI mechanisms are processes that advect PV anomalies into the vicinity of zonal and straight jet stream segments or, alternatively, directly create them there. In either case, the PV anomalies perturb the jet and lead to the formation of a Rossby wave propagating along the jet [see also Davies and Didone (2013), their Fig. 12]. Lower stratospheric positive PV anomalies on the poleward side of a zonal waveguide can result, for instance, from wave breaking on a more northerly waveguide (Martius et al. 2010) or from tropopause polar vortices (TPVs; i.e., radiatively driven mesoscale vortices on the tropopause; Cavallo and Hakim 2009; Kew et al. 2010). In either case, the positive PV anomaly perturbs the jet by its far-field effect and can also act as a precursor to surface cyclogenesis (Kew et al. 2010).

On the equatorward side of the jet, uppertropospheric negative PV anomalies primarily form as a result of diabatic processes (i.e., latent heat release) in ascending air masses. Latent heat release supports the net transport of low-PV air from the lower troposphere up to the typically elevated tropopause (Methven 2015). Moreover, the latent heating is strongest in the lower midtroposphere, where the ascent is most vigorous. This has implications for the Lagrangian PV change in an air parcel, as air parcels located above a diabatic heating maximum experience a decrease in PV (e.g., Wernli and Davies 1997). These two effects lead to the formation or amplification of upper-level negative PV anomalies in the vicinity of the jet and occur often due to large convective systems (Rodwell et al. 2013; Stensrud 2013), warm conveyor belts (WCBs) of extratropical cyclones (Wernli and Davies 1997; Madonna et al. 2014, Martínez-Alvarado et al. 2016), or recurving tropical cyclones (TCs) (Riemer et al. 2008; Grams et al. 2011; Archambault et al. 2013; Grams and Archambault 2016).
A further important process supporting the formation of synoptic-scale Rossby waves is baroclinic instability (Hoskins et al. 1985; Hakim 2003; Heifetz et al. 2004). Baroclinic instability describes the vertical interaction and mutual enforcement of low-level potential temperature anomalies and tropopause-level PV anomalies, which, according to linear theory, does not require finite-amplitude anomalies (Hoskins et al. 1985; Heifetz et al. 2004). Typically, however, in the real atmosphere the triggering of baroclinic instability is regarded as the interaction of a preexisting finite-amplitude upper-level trough with a surface baroclinic zone (Hoskins et al. 1985), which is often referred to as type-B cyclogenesis. The concept of RWI, requiring a straight upper-level jet, is therefore different from this type-B cyclogenesis concept. However, one expects that RWI is often succeeded by baroclinic development, provided RWI occurs in a region of sufficient baroclinicity. In this sense, baroclinic instability is not regarded as a RWI mechanism here. Despite various case studies on RWI, it is unknown whether this list of potential RWI mechanisms is complete and which of these mechanisms occur most frequently. These open questions call for a climatological analysis of RWI.

First steps in this direction have been made by a number of recent studies presenting feature-based climatologies of Rossby wave packets (Glatt and Wirth 2014; Souders et al. 2014; Grazzini and Vitart 2015). Although these studies focused on the entire life cycle of Rossby wave packets, they also presented results that are directly relevant for RWI. Glatt and Wirth (2014) used Hovmöller diagrams of the meridionally averaged wave envelopes of the upper-level meridional wind to identify Rossby wave packets. They found that in winter [December-February (DJF)], most Rossby wave packets form over Eurasia and the North Pacific. In summer, Glatt and Wirth (2014) found generally fewer wave packets, forming most frequently over the North Atlantic. An alternative method also based on wave envelope amplitudes of the upper-level meridional wind (Souders et al. 2014) again identified the most active region of Rossby wave packet formation in the North Pacific, albeit shifted somewhat downstream compared to the findings of Glatt and Wirth (2014). Moreover, Souders et al. (2014) found a strong seasonal cycle with Rossby wave packets being most frequent in winter and least frequent in summer. Grazzini and Vitart (2015) used a similar technique to study the predictability of Rossby wave packets and showed that the presence of a large-amplitude and long-lived Rossby wave packet generally increases the forecast skill. Thus, the main predictability challenge is to correctly forecast the initiation and growth of Rossby waves, which is a further 
motivation for studying the dynamics of RWI. While these studies determined important properties of Rossby wave packets such as their spatial distribution, group velocity, propagation distance, and lifetime, none of them studied the mechanisms leading to RWI.

Here, we focus specifically on these mechanisms and compile an all-season climatology of RWI on the Northern Hemisphere extratropical jet, using the RWI identification algorithm of Röthlisberger et al. (2016). This climatology is then used to study the composite RWI evolution in the most active RWI regions in order to address the following key research questions:

1) Where and how often do RWI events occur on the extratropical jet during the different seasons?

2) Which flow features occur prior to and during RWI and how can they be related to the known RWI mechanisms?

3) Do these flow features typically co-occur or are there different categories of RWI events characterized by different accompanying flow features?

The remainder of this study is organized as follows. In section 2 we introduce the data used in this study and briefly discuss the RWI identification algorithm. Thereafter, we describe basic climatological properties of RWI in section 3. In section 4 we discuss the composite structure of RWI events in winter over the North Pacific and quantify the occurrence and co-occurrence of the most relevant composite features. In section 5 we comment briefly on RWI events over the Tibetan Plateau in summer, before we summarize our main findings in section 6 .

\section{Data and methods}

\section{a. Data}

This study is based on ECMWF interim reanalysis (ERA-Interim) data (Dee et al. 2011) from January 1979 to March 2016. ERA-Interim has a T255 spectral resolution and 60 hybrid sigma-pressure levels. We interpolate these data horizontally to a regular grid with $1^{\circ}$ resolution and vertically to pressure levels and isentropes. In addition, we use the gridded outgoing longwave radiation (OLR) dataset from the National Center for Atmospheric Research (NCAR) (Liebmann and Smith 1996) for the period 1979-2013. We further use the WCB climatology of Madonna et al. (2014), who identified WCBs as strongly ascending trajectories in the vicinity of extratropical cyclones. WCB trajectories are gridded to two-dimensional objects. Hereby, WCB inflow, ascent, and outflow objects result from gridded WCB trajectory positions below $800 \mathrm{hPa}$, between 800 and $400 \mathrm{hPa}$, and above $400 \mathrm{hPa}$, respectively (Sprenger et al. 2017).

\section{b. RWI identification algorithm}

The algorithm of Röthlisberger et al. (2016) identifies locations and times of synoptic-scale wave formation on a formerly undisturbed waveguide. Röthlisberger et al. (2016) discussed in detail the rationale behind their RWI identification algorithm as well as its strengths and weaknesses. Here, their methodology is introduced only briefly.

The algorithm uses the geometry of isentropic contours of 2 potential vorticity units (PVU; 1 PVU $=10^{-6} \mathrm{~m}^{2} \mathrm{~s}^{-1} \mathrm{~K} \mathrm{~kg}^{-1}$ ) (i.e., the dynamical tropopause). For appropriately chosen isentropes, this contour is collocated with the extratropical jet and, hence, its geometry is an excellent indicator for the waviness of the jet (Hoskins et al. 1985; Martius et al. 2010). At each time step, the isentropic 2-PVU contour is extracted from the PV field as a polygon. The waviness of the 2-PVU contour is then analyzed for $60^{\circ}$ longitudinal contour segments, starting every $3^{\circ}$ longitude. For a particular contour segment $j$ at time $t$ a waviness measure $d_{j}^{t}$ is defined as the integrated absolute latitude variations of the contour position over the length of the segment [cf. Eq. (1) in Röthlisberger et al. (2016)]. Hence, large values of jet waviness for a particular contour segment indicate strong meridional undulations, while low waviness values are indicative of a segment with a zonal and straight jet.

The algorithm then identifies wave-free contour segments (i.e., zonally oriented and straight jet segments) that become wavy over time. These contour segments are identified using a waviness threshold $\left(d_{j}^{t}<20^{\circ}\right.$ latitude). The increase of waviness in a formerly zonal and straight contour segment could result either from the downstream dispersion of wave energy along the waveguide or from the initiation of a new wave. Therefore, the algorithm discards contour segments in which a waviness increase might result from downstream development, based on a threshold for the waviness in the $45^{\circ}$ longitude sector upstream of a particular zonal segment.

Finally, RWI events are identified in zonal contour segments that experience a particularly strong increase in jet waviness within $30 \mathrm{~h}$ and, additionally, fulfill the upstream waviness criterion described above. Example cases of RWI events are shown in Röthlisberger et al. (2016). For each RWI event, the algorithm records the time of initiation and the respective Rossby wave initiation segment on the considered isentrope.

\section{c. Extension of the RWI climatology to all seasons}

A crucial condition for the functioning of this algorithm is that the analyzed 2-PVU contour is collocated with the waveguide of interest (here the extratropical 


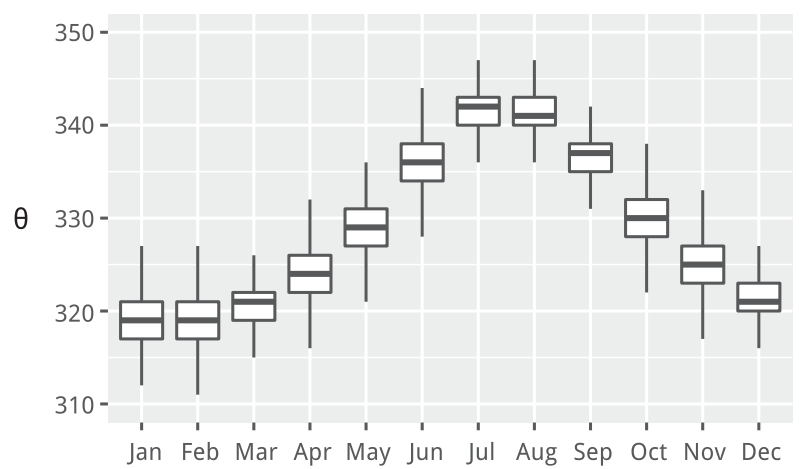

FIG. 1. Standard box-and-whisker plots of the isentropes $\theta(\mathrm{K})$ with maximum mean $\mathrm{PV}$ gradients between $35^{\circ}$ and $65^{\circ} \mathrm{N}$ for all ERA-Interim time steps in the respective month. Outliers are not plotted.

jet). However, both the tropopause and the isentropic surfaces shift vertically throughout the year. Hence, when extending the RWI climatology to all seasons, the isentropic surface of interest must be adjusted such that the respective 2-PVU contours are collocated with the extratropical jet.

As the extratropical Rossby waveguide is collocated with particularly strong isentropic PV gradients (Martius et al. 2010), one ideally chooses those isentropic surfaces that exhibit the strongest PV gradients in the latitudinal band of the extratropical jet $\left(\sim 35^{\circ}-65^{\circ} \mathrm{N}\right)$. Figure 1 depicts the isentropic surfaces with the strongest mean PV gradient between $35^{\circ}$ and $65^{\circ} \mathrm{N}$ for all ERA-Interim time steps between 1979 and 2015 as box plots. A clear seasonal cycle is apparent, representing the seasonal cycle in the isentropic position of the extratropical jet. Based on Fig. 1 we chose to analyze the 2-PVU contour geometry on the isentropic surfaces shown in Table 1 and further refer to these isentropic surfaces as extratropical jet isentropes. They are used to compile the all-season climatology of RWI on the extratropical jet for the period January 1979-March 2016.

\section{d. Anomaly composites with respect to random zonal jet configurations}

In sections 4 and 5 we use anomaly composites of various variables to study the evolution of the composite RWI. Caution is needed when choosing the appropriate climatology for calculating anomalies during RWI. Simply calculating anomalies of some variable $V$ (e.g., PV) with respect to, for example, its monthly mean leads to considerable anomalies at the time of initiation. However, these anomalies partly result from the fact that, by design, RWI only occurs in contour segments with a zonal jet configuration while the same segment may be wavy at other time steps comprising the respective monthly mean. Hence, one compares zonal and
TABLE 1. Extratropical jet isentropes (K).

\begin{tabular}{llllllllllll}
\hline Jan & Feb & Mar & Apr & May & Jun & Jul & Aug & Sep & Oct & Nov & Dec \\
\hline 320 & 320 & 320 & 325 & 330 & 335 & 340 & 340 & 335 & 330 & 325 & 320
\end{tabular}

straight jet configurations with the full climatology. However, only roughly $0.3 \%$ of all zonal segments are initiation segments (Fig. 2; to be discussed in section 3). Therefore, anomalies with respect to the full climatology are not generally relevant for RWI. When studying the signals relevant for RWI, it therefore provides more insight to compare the $V$ field at the time of initiation only with other time steps with a zonal jet configuration in the respective segment.

The objective of the procedure described below is thus to isolate the differences in $V$ between zonal jet configurations with and without RWI. For a given set of RWI events we first calculate the composite of the full $V$ fields at the times of initiation, centered spatially on the starting longitude and mean latitude of the initiation segment. Then, this composite field is compared to 1000 randomly constructed composites that are all based on zonal jet configurations only. For a particular RWI event at time $t$ in contour segment $s_{j}^{t}$ we choose random dates tr such that $s_{j}^{\text {tr }}$ is zonal $\left(d_{j}^{\text {tr }}<20^{\circ}\right.$ latitude $)$ but no RWI event occurred within a 24 -h time and $45^{\circ}$ longitude window. Additionally, the random dates tr are chosen from the same month as $t$ in order to obtain the same seasonal distribution in the random dates as for the true RWI events. The mean over these 1000 random composites is then considered as the $V$ climatology for zonal jet configurations without RWI; consequently, $V$ anomalies are calculated with respect to this climatology. To analyze the time evolution before and after RWI, lagged composites are constructed with the respective lags added to both the true and the random times of initiation.

Statistically significant anomalies are identified in two steps. We test the hypothesis that the composite values are equal to the median of the random composite values and first estimate the respective $p$ value at each grid point independently, by comparing the composite value to the distribution of random composite values at the same grid point. Hereby, a $p$ value of 0 is assigned if the composite value is outside the distribution of the random composite values. Then, following Wilks (2016), we apply the false discovery rate (FDR) test of Benjamini and Hochberg (1995) with a maximum FDR of 0.1 to the field of $p$ values. This test takes into account the number of tests carried out simultaneously as well as the distribution of the corresponding $p$ values. In this way it effectively controls the proportion of falsely rejected null hypotheses (FDR). A detailed review of the use of this 


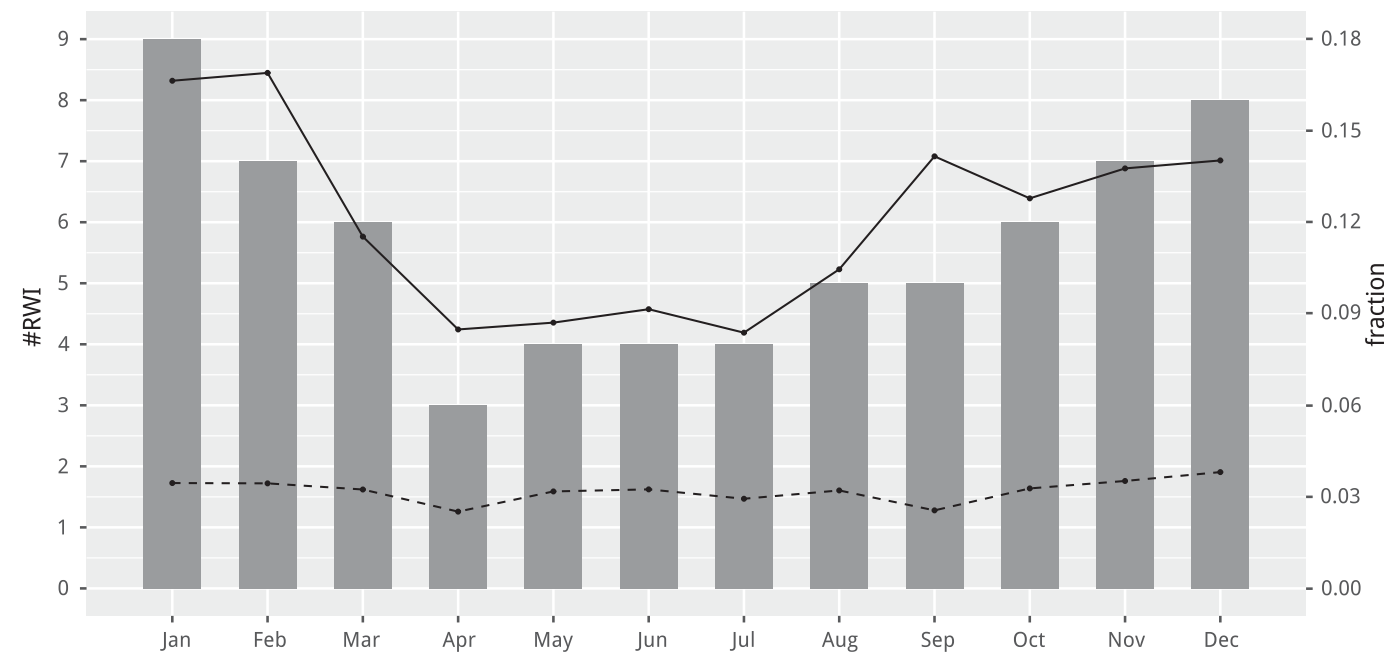

FIG. 2. Median hemispheric number of RWI events per month (bars), median hemispheric fraction of zonal segments (black solid line, right $y$-axis values), and median number of RWI events per zonal segment multiplied by 10 (black dashed line, left $y$-axis values).

test for multiple testing applications in atmospheric sciences is given by Ventura et al. (2004) and Wilks (2016).

\section{RWI climatology on the extratropical jet}

In total, 2577 RWI events on the Northern Hemisphere extratropical jet are identified in the ERA-Interim dataset in January 1979-March 2016. The monthly number of RWI events exhibits a clear seasonal cycle (Fig. 2), with highest frequencies in winter (DJF; 7-9 events per month in the median) and lowest frequencies in late spring and summer (April-July; 4-5 events per month). However, the year-to-year variability in the number of RWI events per month is large with 4-14 RWI events in December and 0-11 RWI events in June (not shown).

The seasonal cycle in the frequency of RWI events (their hemispheric number per month) covaries with the number of zonal segments per month (Fig. 2). Consequently, the number of RWI events per zonal segment remains relatively constant throughout the year at roughly $0.3 \%$ in the median, implying that very few (i.e., roughly 3 out of 1000) zonal contour segments are identified as RWI segments (Fig. 2).

In winter (DJF), RWI events occur mostly over the western and central North Pacific and over the North Atlantic (Fig. 3a). In spring [March-May (MAM)] and summer [June-August (JJA)], the RWI maximum over the North Pacific shifts toward the west and is located over the Tibetan Plateau in summer (Figs. 3b,c). In fall [September-November (SON)], this maximum in the Asian-Pacific region moves back toward the central North Pacific, and the number of RWI events is slightly larger than in spring (Fig. 3d). Over the North Atlantic, the number of RWI events exhibits a different seasonal cycle with only few RWI events in spring and fall (Figs. 3b,d), but frequent RWI events in winter and summer.

The spatial distribution and the monthly numbers of RWI events are in accordance with Rossby wave packet climatologies. Souders et al. (2014) found approximately 10 Rossby wave packets forming per month in January and 3 Rossby wave packets in July, which compares well with our results (Fig. 2). Likewise, the spatial distribution of initiation segments closely resembles that of Rossby wave packet formation points [compare Fig. 3 herein with Fig. 3a in Souders et al. (2014)]. Even though not every RWI event must develop into a wave packet a close agreement between RWI and Rossby wave packet formation is expected. For winter, our results are also in good qualitative agreement with Glatt and Wirth (2014). In summer, however, Glatt and Wirth (2014) identified more Rossby wave packets forming in the North Atlantic than in the North Pacific region, in contrast to the results presented here and by Souders et al. (2014). Further, the high frequency of RWI events over the Tibetan Plateau in summer is consistent with Schiemann et al. (2009), who found that the jet is often located north (south) of the Himalayas in summer (winter).

\section{RWI over the North Pacific in winter}

\section{a. Comparing the RWI climatology to other mean fields}

In the following, the focus of this study is on the processes leading to and occurring during the initiation of synoptic-scale Rossby waves. Since RWI events are 

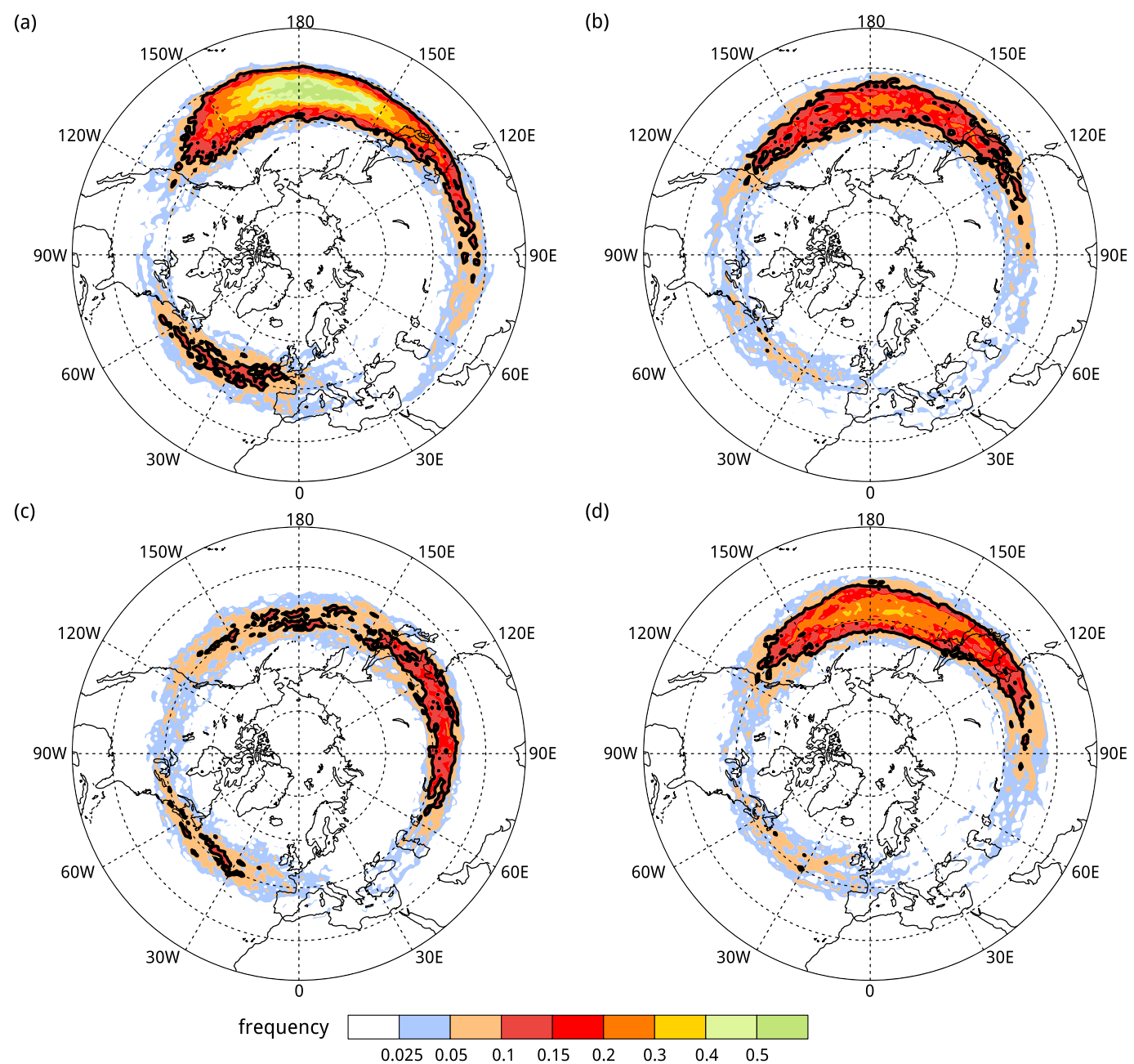

FIG. 3. Seasonal climatology of gridded RWI segments (freqency is per month and per $1^{\circ} \times 1^{\circ}$ grid box) for (a) DJF, (b) MAM, (c) JJA, and (d) SON. The value of 0.1 is highlighted by the black contour.

most frequent over the North Pacific in winter (Fig. 3a), we restrict much of the following investigation to RWI events occurring in the segments starting between $100^{\circ} \mathrm{E}$ and $120^{\circ} \mathrm{W}$ in winter and further refer to them as DJF Pacific RWI events. This excludes almost all cases where RWI might be related to transitioning tropical cyclones. This specific type of RWI has been addressed in a study by Riboldi et al. (2017, manuscript submitted to Mon. Wea. Rev.). The gridded RWI segments of all DJF Pacific RWI events are depicted in Fig. S1a in the supplemental material.

We start by comparing the climatological distribution of RWI events with the climatological fields of some variables that might be of relevance for RWI. The main initiation regions over the western North Pacific and the North Atlantic are located downstream of the planetary-scale troughs and downstream of the Himalayas and the Rocky Mountains, respectively (Fig. 4a). By construction of the
RWI climatology, the frequency of zonal jet segments is large within the main initiation regions; however, the initiation segment frequencies are highest just downstream of the highest zonal jet segment frequencies and the climatologically strongest and most zonal jets (Figs. 4a,b).

As expected from the thermal wind relationship, the climatological low-level meridional temperature gradient is strong in the main initiation regions; however, the highest initiation segment frequencies occur downstream of the strongest low-level baroclinicity (Fig. 4c). Moreover, RWI events occur in regions where, climatologically, condensational heating $(\mathrm{CH}$; vertically averaged between 1000 and $300 \mathrm{hPa}$ ) is largest (Fig. 4d).

\section{b. The composite North Pacific RWI event in winter}

We now use anomaly composites to study the evolution of upper-level PV anomalies, surface cyclones, diabatic processes, WCB activity, and OLR anomalies 
(a)

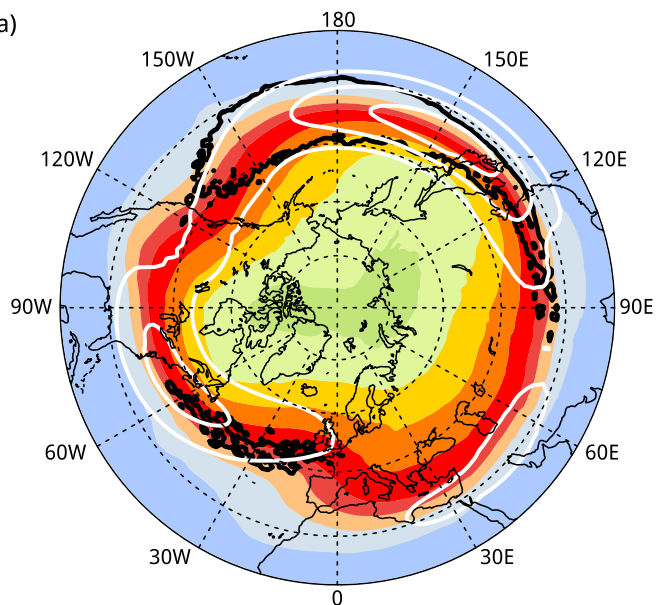

PVU

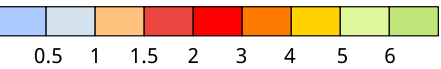

(c)

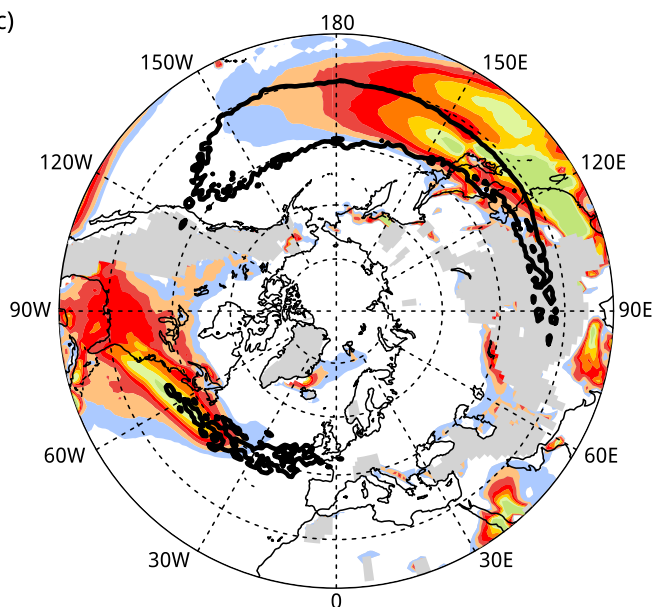

$\mathrm{K} \mathrm{m}^{-1} 10^{-6}$

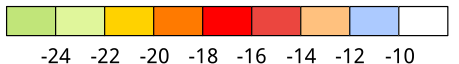

(b)

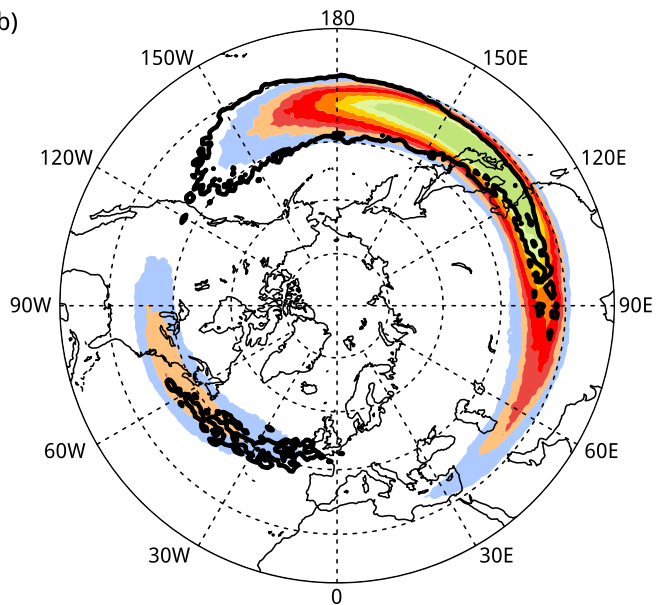

frequency

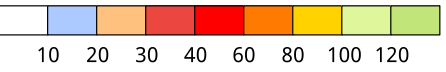

(d)

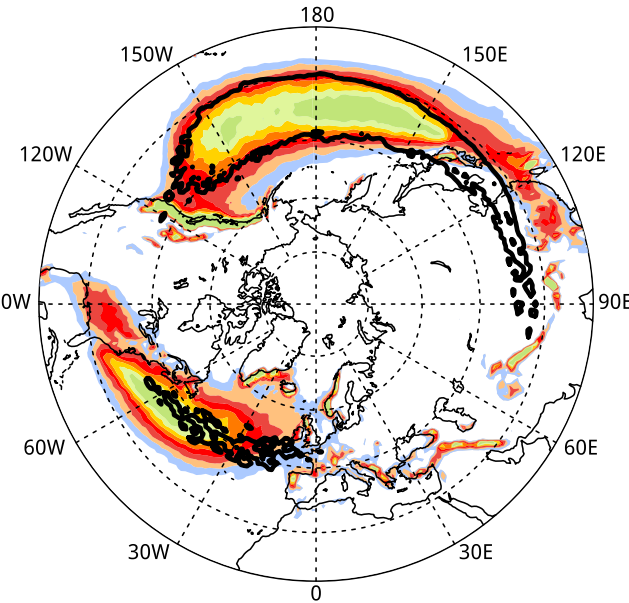

$\mathrm{K}(6 \mathrm{~h})^{-1}$

FIG. 4. DJF climatology of (a) PV (shading) and wind velocity (white contours, depicting 30, 40, and $50 \mathrm{~m} \mathrm{~s}^{-1}$ ) on the $320-\mathrm{K}$ isentropic surface, (b) frequency of zonal segments on $320 \mathrm{~K}$ (segments per month per $1^{\circ} \times 1^{\circ}$ grid box), (c) meridional gradient of equivalent potential temperature at $850 \mathrm{hPa}$, and (d) vertically averaged (1000-300 hPa) condensational heating. Gray shading denotes missing values resulting from topography. The black contour in all panels depicts a RWI frequency of 0.1 segments per month per $1^{\circ} \times 1^{\circ}$ grid box.

prior to, during, and after the 624 DJF Pacific RWI events. For OLR anomalies only RWI events from the period 1979-2013 are considered (579 events) due to lack of OLR data thereafter.

At lag $-72 \mathrm{~h}$ an upstream wave train arches toward the initiation segment from the northwest (Fig. 5a). This feature is apparent in the upper-level $(320 \mathrm{~K}) \mathrm{PV}$ and the 250-hPa streamfunction (SF) fields (Fig. 5a), as well as in sea level pressure (SLP; Fig. 5b). Part of this upstream wave train is a pronounced positive $\mathrm{PV}$ anomaly centered at $45^{\circ} \mathrm{W}$ and $20^{\circ} \mathrm{N}$ (the longitude and latitude values in Figs. 5, 6, and 7 are relative to the location of the RWI segment). This stratospheric structure will further be referred to as upstream PV anomaly. A weak negative SLP anomaly at $20^{\circ} \mathrm{W}$ and $15^{\circ} \mathrm{N}$ (ahead of the upstream PV anomaly) is present already at this stage and will intensify as the composite wave grows. Additionally, a ridge is present downstream of the initiation segment, at $80^{\circ} \mathrm{E}$, visible as a positive SLP (negative PV) anomaly exceeding $+4 \mathrm{hPa}$ (Fig. 5b). A comparison of Fig. 5a and Figs. 5c,e,g reveals that this downstream ridge is stationary, in contrast to the clearly transient upstream wave train. Finally, a positive SF anomaly is located just upstream and to the south of the initiation segment, at $10^{\circ} \mathrm{S}$ and $30^{\circ} \mathrm{W}$ (Fig. 5a), which indicates a strengthened subtropical anticyclone. 

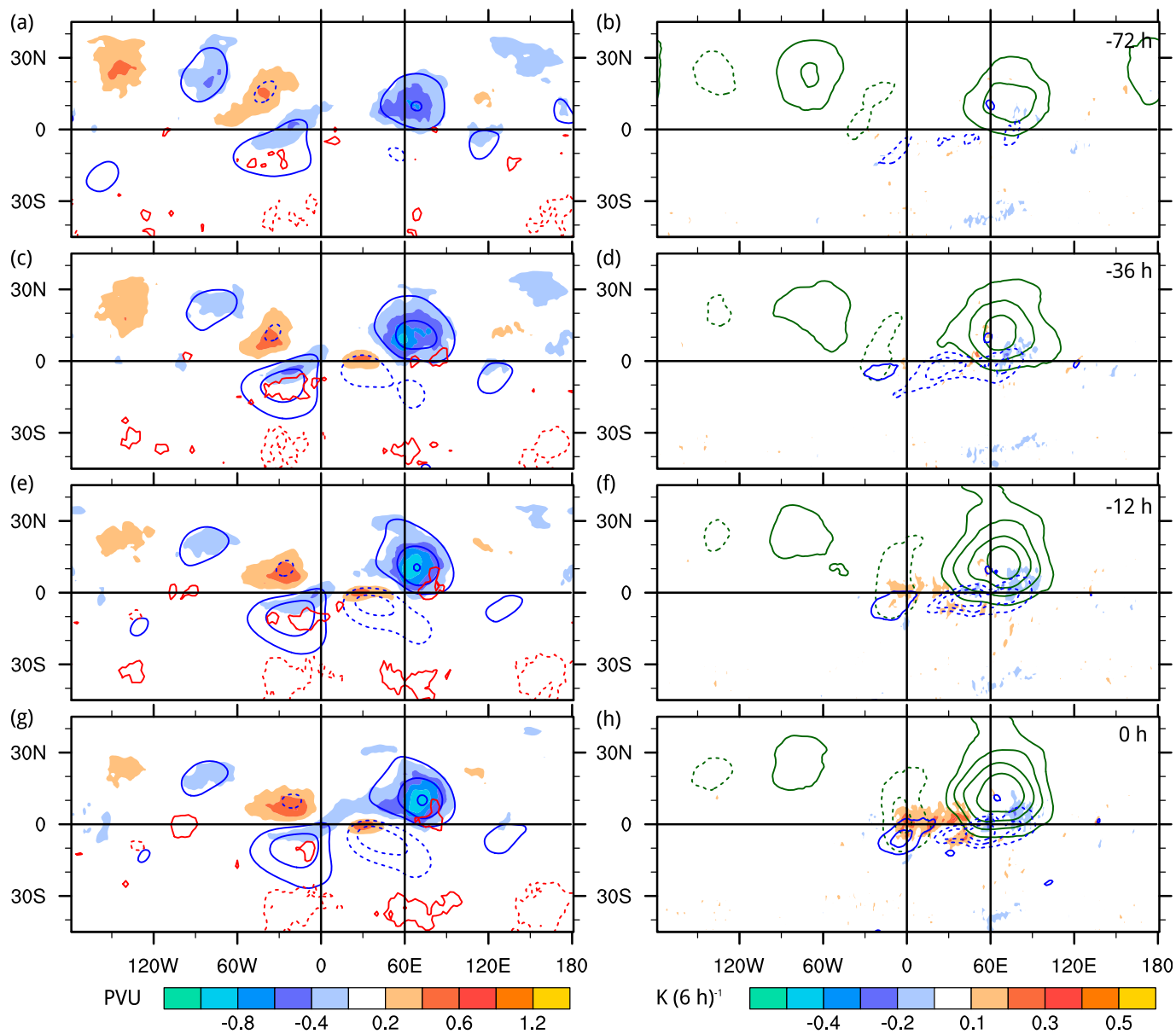

FIG. 5. Time-lagged composites of various variables for DJF North Pacific RWI events centered on the westernmost longitude and the mean latitude of the respective initiation segment. (left) PV anomaly at $320 \mathrm{~K}$ (shading), $\mathrm{SF}$ anomaly at $250 \mathrm{hPa}$ of $\pm 4, \pm 8, \pm 12$, and $\pm 16 \times 10^{6} \mathrm{~m}^{2} \mathrm{~s}^{-1}$ in solid and dashed blue contours for positive and negative values, respectively. Solid (dashed) red contours depict OLR anomalies of $+4(-4) \mathrm{W} \mathrm{m}^{-2}$. (right) Vertically averaged $(1000-300 \mathrm{hPa}) \mathrm{CH}$ anomaly [shading; $\mathrm{K}(6 \mathrm{~h})^{-1}$ ]. Solid and dashed green contours show positive and negative SLP anomalies, respectively, of $\pm 8, \pm 6, \pm 4$, and $\pm 2 \mathrm{hPa}$. Solid and dashed blue contours depict positive and negative IVT anomalies, respectively, of $\pm 30, \pm 60$, and $\pm 90 \mathrm{~kg} \mathrm{~m}^{-1} \mathrm{~s}^{-1}$. Results are shown at lag (a),(b) $-72,(\mathrm{c}),(\mathrm{d})-36$, (e),(f) -12 , and (g),(h) at $0 \mathrm{~h}$. Only statistically significant anomalies are shown.

At lag $-36 \mathrm{~h}$, (Figs. 5c,d) the OLR anomaly field shows negative values below $-4 \mathrm{~W} \mathrm{~m}^{-2}$ at $30^{\circ} \mathrm{W}$ and $35^{\circ} \mathrm{S}$, which indicates active tropical convection (at about $0^{\circ}-10^{\circ} \mathrm{N}$ ) to the west of the initiation segment. Also, both the subtropical anticyclone (now strongest at $30^{\circ} \mathrm{W}$ and $15^{\circ} \mathrm{S}$ ) and the downstream ridge have strengthened. Moreover, at the southern fringe of the negative SLP anomaly at $20^{\circ} \mathrm{W}$ and $0^{\circ}$ longitude, a positive anomaly of integrated vapor transport [IVT; see Froidevaux and Martius (2016) for the details of its computation] has formed (Fig. 5d). In the center of the initiation segment, at $30^{\circ} \mathrm{E}$ and $10^{\circ} \mathrm{S}$, coherent positive $\mathrm{PV}$ and negative SF anomalies have appeared. One day later, at lag $-12 \mathrm{~h}$ (Figs. 5e,f), the negative SLP anomaly has moved approximately $10^{\circ}$ downstream and, collocated with the positive IVT anomaly, the frequency of warm conveyor belt inflow (WCBI) objects is significantly increased (Fig. 7a).

At the time of RWI (lag 0h; Figs. 5g,h), coherent positive anomalies of vertically averaged $\mathrm{CH}$ appear between $10^{\circ} \mathrm{W}$ and $50^{\circ} \mathrm{E}$ around $0^{\circ}$ latitude, collocated with increased WCB inflow and ascent (Figs. $5 \mathrm{~h}$ and $7 \mathrm{~b}$ ). Moreover, the negative SLP anomaly has intensified and the SF anomalies now reveal a clear deformation flow pattern, with the axis of dilatation (contraction) oriented in the meridional (zonal) direction (Figs. 5g,h). The following four anomaly features contribute to this pattern: the upstream PV anomaly, which is part of the upstream wave train, the strengthened subtropical anticyclone, the downstream ridge, and the negative SF 

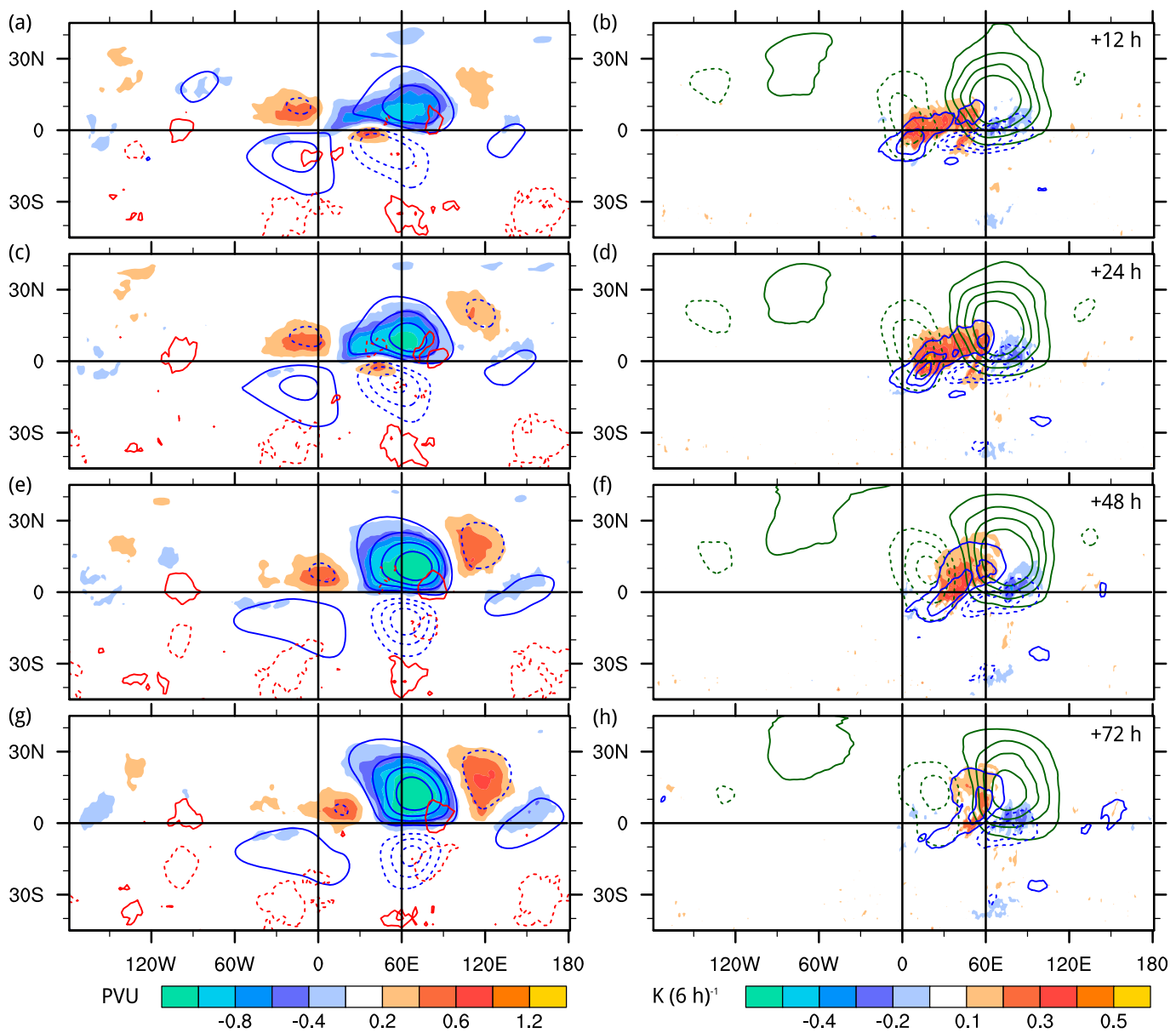

FIG. 6. As in Fig. 5, but for lags of (a),(b) +12 , (c),(d) +24 , (e),(f) +48 , and (g),(h) $+72 \mathrm{~h}$.

anomaly that formed in the center of the initiation segment around lag $-36 \mathrm{~h}$. This pattern promotes a stronger jet upstream and a weaker jet within the RWI segments compared to random zonal segments.

During the early growing phase of the composite wave (lags +12 and $+24 \mathrm{~h}$ ) many of the features discussed above strengthen. The SLP anomaly of the forming cyclone intensifies to values below $-6 \mathrm{hPa}$ at its center (Fig. 6d), while the positive warm conveyor belt ascent (WCBA) anomalies also become stronger [up to 6 percentage points (pp)] and widespread $\mathrm{WCB}$ outflow (WCBO) anomalies appear (up to 9 pp; Fig. 7c). The WCB ascent is collocated with pronounced positive $\mathrm{CH}$ anomalies and IVT anomalies (Figs. 6b and 7c). Also, consistent with the WCBO anomaly, the negative PV anomaly associated with the downstream ridge expands eastward to $30^{\circ} \mathrm{E}$ and strengthens to reach values below $-1.2 \mathrm{PVU}$, which indicates ridge building within the RWI segment. The deformation flow pattern persists during lags +12 and $+24 \mathrm{~h}$ (Figs. $6 \mathrm{a}, \mathrm{c}$ ) and downstream development is evident, with a positive $\mathrm{PV}$ and negative
SF anomaly appearing and strengthening at $20^{\circ} \mathrm{N}, 120^{\circ} \mathrm{E}$, downstream of the downstream ridge (Figs. 6a,c).

Downstream development continues over the successive $48 \mathrm{~h}$ and a wave train arches away from the RWI segment at lag +48 and $+72 \mathrm{~h}$ (Figs. 6e,g). The WCBA anomaly reaches its peak strength at $+24 \mathrm{~h}$, whereas the WCBO anomalies do not weaken considerably until lag +72 h (Fig. 7d). Similarly, the surface cyclone reaches its maximum strength between lags +24 and $+48 \mathrm{~h}$ and weakens thereafter (Figs. 6f,h). Note that a weakening of composite structures does not necessarily imply that the features themselves weaken; it may also be that their positions become less coherent, leading to a weaker signal in the averaged fields.

\section{c. Composite Hovmöller diagrams}

More insight into the temporal evolution of tropical and extratropical features relative to the location and time of DJF North Pacific RWI can be gained from composite Hovmöller diagrams (Fig. 8). They have been constructed in the same way as Figs. 5-7, and depict 


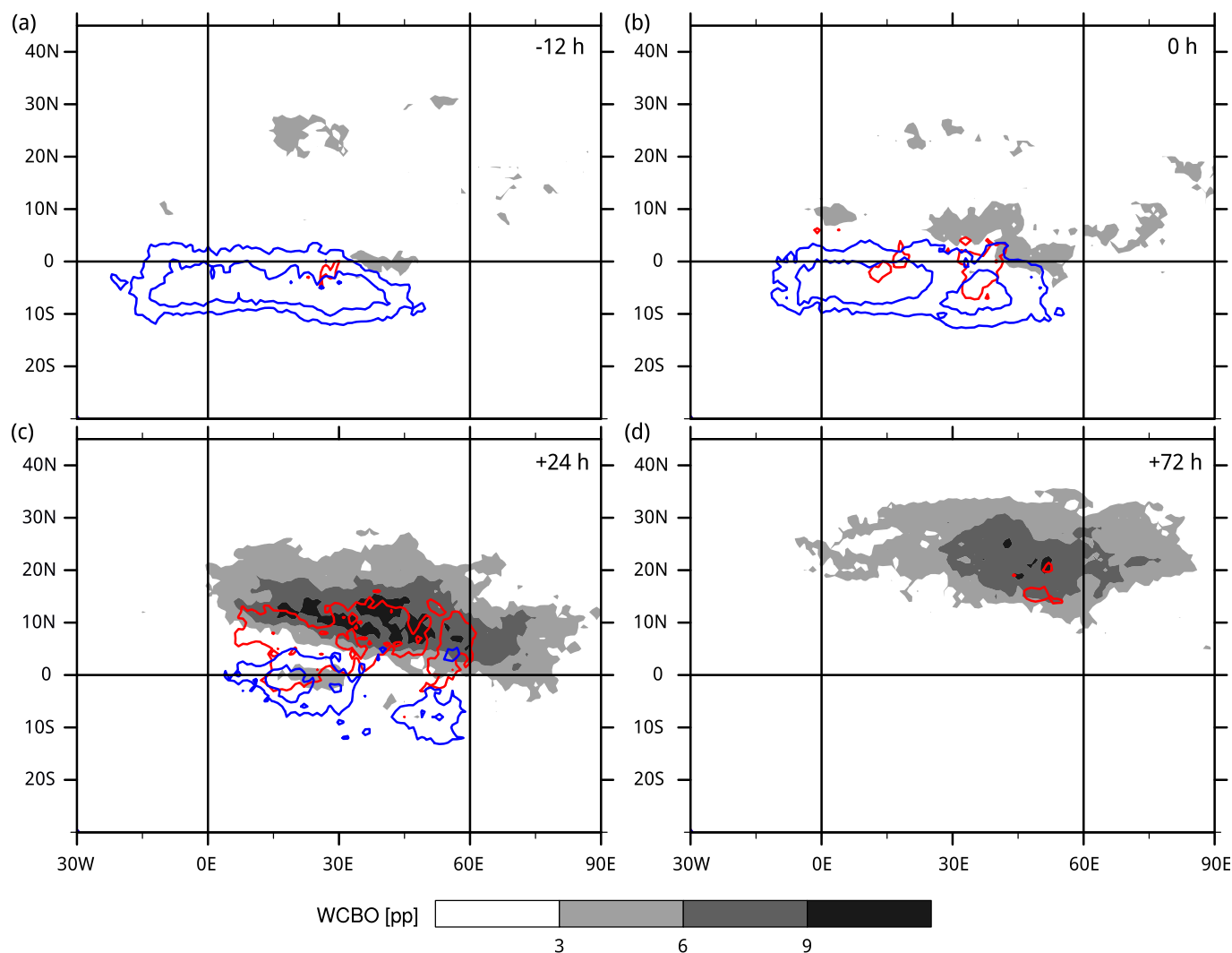

FIG. 7. Time-lagged composites of positive WCBO frequency anomalies (shading; pp) for DJF Pacific RWI events at lags of (a) -12 , (b) 0 , (c) +24 , and (d) $+72 \mathrm{~h}$. Blue and red contours depict WCBI and WCBA frequency anomalies of 4 and $8 \mathrm{pp}$, respectively.

anomalies relative to the mean of 1000 Hovmöller composites centered on randomly chosen zonal jet segments. Figure 8a shows the composite meridional wind anomaly $v$ on 320-K isentropic surface, averaged in a band of $\pm 5^{\circ}$ latitude around the 2-PVU contour. This type of Hovmöller diagram was introduced by Martius et al. (2006) and in the context of multiple waveguides it is particularly suitable to analyze the waveguides separately. Approximately 4 days prior to the time of RWI, the downstream ridge and the upstream PV anomaly appear in the Hovmöller diagram of $v$ on $320 \mathrm{~K}$ (Fig. 8a). The upstream wave train is clearly visible in the composite Hovmöller diagram of $v$ on $310 \mathrm{~K}$ (Fig. 8b), constructed in the same way as Fig. 8a. This indicates that the upstream wave train propagates on a more northerly Arctic waveguide across Asia and thus does not affect the waviness of the extratropical jet prior to RWI. By construction of the RWI climatology, $v$ anomalies on $320 \mathrm{~K}$ are weak in the initiation segment at the time of initiation. Thereafter, ridge building as well as downstream development occurs and leads to a strong increase in jet waviness (Fig. 8c). The composite Hovmöller diagram of IVT averaged between $30^{\circ}$ and $60^{\circ} \mathrm{N}$ shows coherent positive anomalies after day -3 (Fig. 8d) whereas the composite Hovmöller diagram of $\mathrm{CH}$, averaged in the same latitude band (Fig. 8e), shows an abrupt onset of positive anomalies at the time of initiation.

In contrast, the composite Hovmöller diagram of OLR averaged between $22.5^{\circ} \mathrm{S}$ and $22.5^{\circ} \mathrm{N}$ exhibits stationary anomalies that are present already more than 20 days prior to the time of initiation (Fig. 8f). Since the Hovmöller composites in Fig. 8 have been centered on the longitude of RWI, this indicates that RWI preferentially occurs just east of particularly active tropical convection. Thus, variations in tropical convection (on longer than synoptic time scales) serve as a geographical anchor for RWI (i.e., they are one of the factors determining the longitude where RWI events occur). The mechanisms by which RWI in the extratropics is affected by tropical convection certainly merit further investigation; however, this is not the focus of this study.

\section{d. Key ingredients of North Pacific RWI events in winter}

The composites discussed above indicate the key relevance of four extratropical ingredients for RWI. First, 

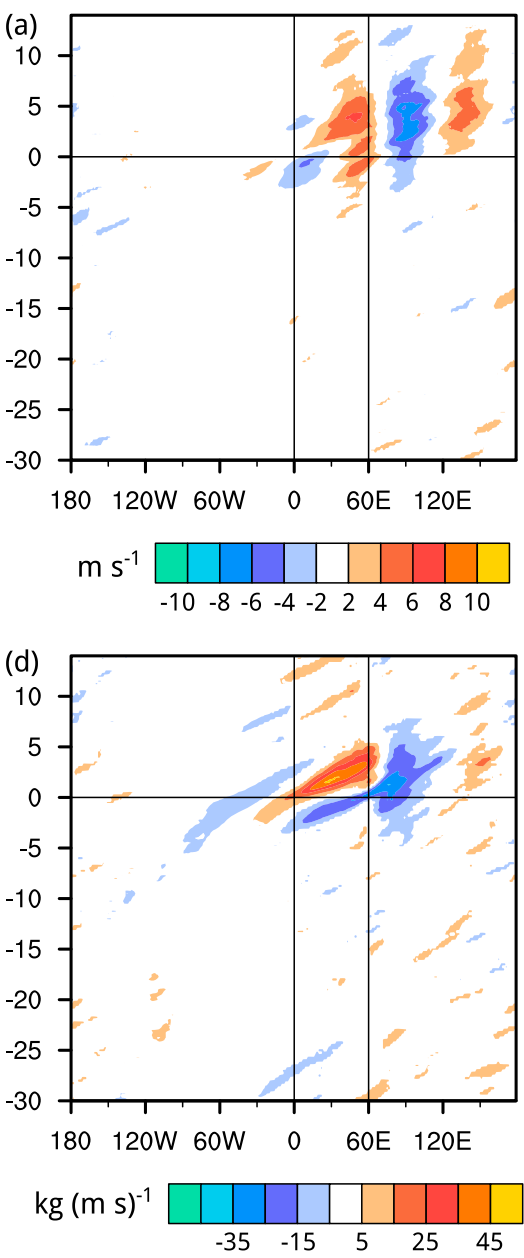
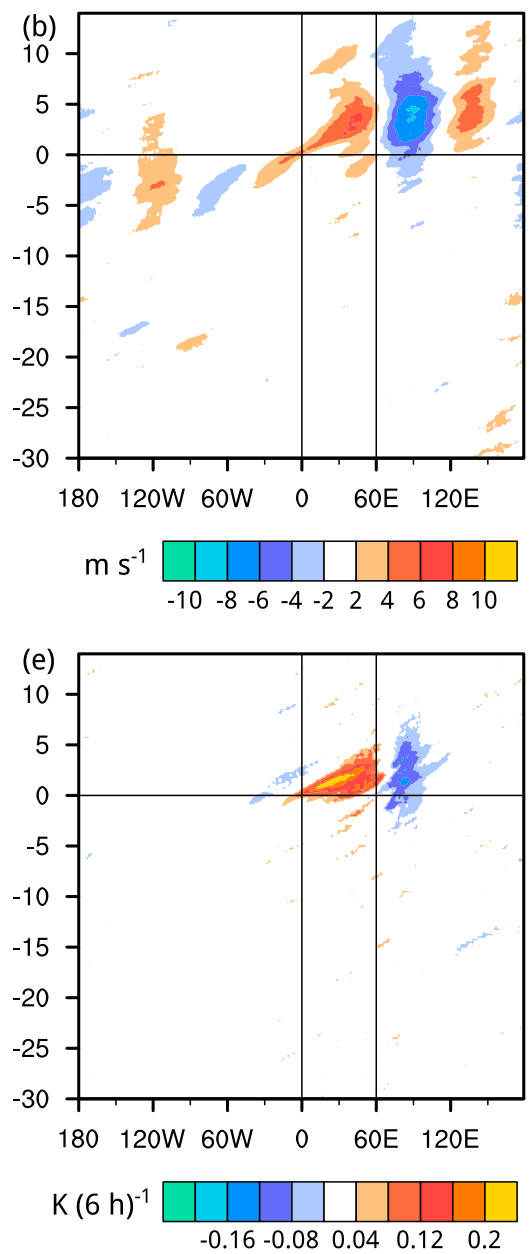

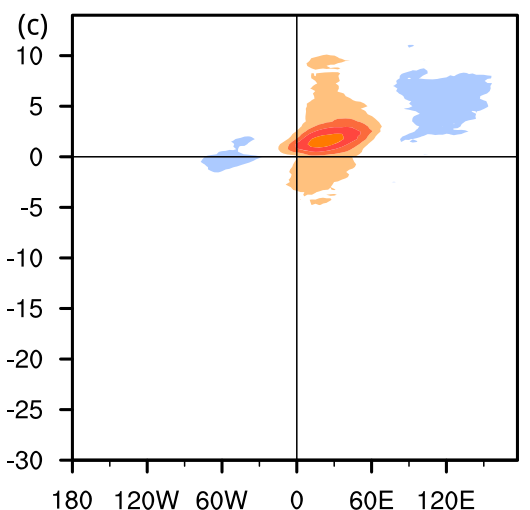

degrees
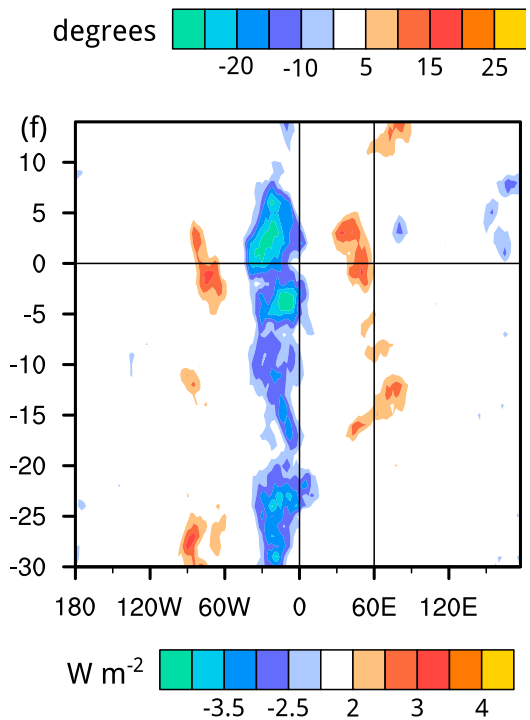

FIG. 8. Composite Hovmöller diagrams of (a) meridional wind anomaly on $320-\mathrm{K}$ isentropic surface in a band of $\pm 5^{\circ}$ latitude around the 2-PVU contour. (b) As in (a), but for the 310-K isentropic surface. (c) Jet waviness anomaly on $320 \mathrm{~K}$, (d) IVT anomaly between $30^{\circ}$ and $60^{\circ} \mathrm{N}$, (e) vertically averaged $(1000-300 \mathrm{hPa}) \mathrm{CH}$ anomaly between $30^{\circ}$ and $60^{\circ} \mathrm{N}$, and (f) OLR anomaly between $22.5^{\circ} \mathrm{S}$ and $22.5^{\circ} \mathrm{N}$. The longitude in (c) depicts the starting longitude of the segments. In all panels the $y$ axis depicts the time lag in days. The vertical lines depict the extent of the initiation segment and the horizontal line depicts the time of initiation. Only statistically significant anomalies are shown.

Fig. 5 reveals the presence of a positive PV anomaly approaching the zonal jet from its poleward side. Moreover, this southwest-northeast-tilted feature is part of an upstream wave train. It is therefore consistent with the initiation of Rossby waves due to waveguide interaction induced by breaking Rossby waves on a more poleward waveguide (Martius et al. 2010) or by TPVs (Cavallo and Hakim 2009; Kew et al. 2010) and also confirms that disturbances propagating along the Arctic waveguide across Asia act as precursors to RWI over the North Pacific (Chang and Yu 1999; Hakim 2003; Torn and Hakim 2015).

Second, within this growing wave moisture transport occurs in the WCB inflow region prior to RWI and is followed by vigorous latent heat release in the WCB ascent region (Figs. 5-7). This leads to strong ridge building between lags 0 and $+48 \mathrm{~h}$, which is collocated with positive WCB outflow anomalies and thus is a clear indication for diabatically driven wave initiation and amplification. Third, the forming composite wave exhibits a baroclinic structure (Figs. 5 and 6) with the deepening SLP anomaly located ahead of the upstream PV anomaly.

Fourth, a pronounced downstream ridge is apparent already three days prior to the time of initiation. This downstream ridge contributes to a deformation flow pattern over the RWI segment. Hence, synoptic-scale Rossby waves tend to form and amplify upstream of a preexisting ridge in regions of large-scale upper-level deformation, with the axis of dilatation aligned meridionally. Similar behavior of synoptic-scale waves has been described in the context of atmospheric blocking. For example, Berggren et al. (1949) already observed 
that synoptic-scale waves tend to amplify meridionally and contract zonally when approaching an upper-level ridge, due to large-scale deformation in regions of diffluent jets. Later, Shutts (1983) built on this idea to explain how meridionally amplifying synoptic-scale eddies approaching an atmospheric block lead to its persistence.

It would now be interesting to assess the relative importance of these four ingredients for individual RWI events. However, a quantitative assessment of their role would require PV inversion techniques [e.g., as in Teubler and Riemer (2016)] and modeling studies for each case. Because of the large number of RWI events we opt for a much simpler approach and instead quantify the frequency of occurrence and co-occurrence of the previously described composite features.

\section{e. Frequency and co-occurrence of the composite flow features}

Eight feature indices are defined, each capturing the presence and size of one composite feature in individual RWI events. Indices for the following features are calculated: the upstream PV anomaly (PVUI), the downstream ridge (PVDI), the forming cyclone (SLPI), the positive IVT and CH anomalies (IVTI and $\mathrm{CHI}$, respectively), the active tropical convection (OLRI), the strengthened subtropical anticyclone (SFI), and the positive upper-level PV anomaly in the center of the initiation segment (PVCI). To calculate the indices for each RWI event we use the anomaly fields of the respective variable at lag $0 \mathrm{~h}$ in a subjectively chosen box covering the respective composite feature (Fig. 9). The indices are then calculated as the fraction of grid points with anomaly values exceeding the strongest composite anomaly. The choice of this threshold is arbitrary but helps with the interpretation of the index values. For example, for the PVUI, an index value of $0.25(0)$ for a particular RWI event implies that $25 \%$ (none) of the PVUI box is covered by a positive $\mathrm{PV}$ anomaly stronger than the largest positive composite PV anomaly in this box.

Some indices span the entire range from 0 to 1 (e.g., SLPI; Fig. 10h), while other indices are constrained to a much smaller range and lower values (e.g., CHI; Fig. 10e). This results from the different sizes of the relevant features with respect to the selected box size. For example, $\mathrm{CH}$ anomalies such as convective systems and WCB ascent are of small spatial scale compared to the $\mathrm{CHI}$ box, while cyclones and anticyclones can be as large as the SLPI box. Moreover, the shape of the distributions varies considerably. For example, the PVUI distribution peaks between 0.4 and 0.6 . Its 20 th percentile is 0.26 , indicating that in $80 \%$ of the RWI events a positive PV anomaly stronger than the composite PV anomaly covers at least $26 \%$ of the PVUI box. Similarly, the distributions of PVDI, OLRI, IVTI, and $\mathrm{CHI}$ also point to a frequent presence of these features. The 20th percentiles of IVTI and CHI are considerably lower at 0.10 and 0.09 , respectively, due to the smaller range of these indices. In contrast to all other indices, the distributions of SFI and SLPI peak right at the lower end of their range. Their 20th percentiles are 0.02 and 0.09 , respectively, revealing that for more than $20 \%$ of the cases these features are either absent or cover only a marginal fraction (less than $2 \%$ and $9 \%$ respectively) of the respective box, despite the fact that both features can be as large as the boxes themselves (maximum index values of 1). Therefore, in a considerable number of RWI events, a strengthened subtropical anticyclone and/or a surface cyclone located in the same region as the respective composite feature are missing.

In a next step, total and partial Spearman rank correlations between the different indices are calculated [i.e., ordinary Pearson correlation and partial correlation coefficients of the ranked index values; see chapter 3.5.3 in Wilks (2011) and Kim (2015) for details] to identify preferred combinations of features (positively correlated indices), mutually exclusive features (anticorrelated indices), and independent features (uncorrelated indices; Tables 2 and 3). The total correlations between the indices are generally weak, with few exceptions (Table 2). The strongest correlations are found between IVTI and SLPI (0.74) and between IVTI and CHI (0.49). Despite being weak, some of the correlations are statistically significant and thus allow us to draw some inferences on the preferred co-occurrence of the different features.

To visualize the correlations, we adopt the approach of Graf et al. (2017) and perform a principal component analysis (PCA) on the standardized indices and project the RWI events onto the first two principal components (PC1 and PC2; Fig. 11), which explain 29.1\% and 20.9\% of the total variance, respectively (Table S1 in the supplemental material). Each index is indicated in Fig. 11 as a radial vector, defined by its correlations with the first two PCs (Table S2 in the supplemental material). Long vectors contribute strongly to the first two PCs. Moreover, vectors pointing into similar (opposite) directions indicate correlated (anticorrelated) indices, while vectors at a right angle represent uncorrelated indices. Note that exact quantitative inferences on the correlations between the indices could only be drawn from these arrows if the first two PCs explained $100 \%$ of the variance in the original eight-dimensional index space [see Jolliffe (2002) and Wilks (2011) for details]. Here, we 

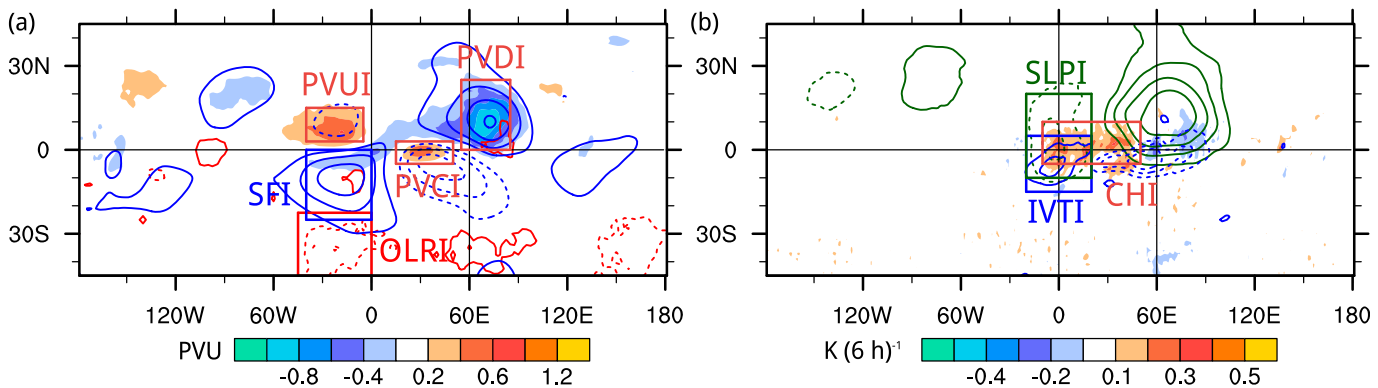

FIG. 9. Boxes used for the definition of the feature indices. (a),(b) The shading and contours are as in Figs. 5g,h.

use Fig. 11 to qualitatively visualize the correlations already shown in Table 2 and the correctness of the inferences drawn from the arrows in Fig. 11 is easily checked by comparison with Table 2 .

PC1 is strongly correlated with SLPI, IVTI, and CHI, and, somewhat less strongly, with PVUI (Fig. 11). Each of these indices is related physically to the forming cyclone and the latent heating therein. The correlation between these indices implies that during individual RWI events a pronounced upstream PV anomaly, a strong SLP minimum, strong moisture transport, and vigorous condensational heating tend to co-occur, and the same is true for the combination of weak values of these four indices.

PC2 is correlated with the indices OLRI, SFI, and PVDI. The positive correlations among these indices is physically plausible: It is well known that active tropical convection over the western tropical Pacific (OLRI) leads to a stronger subtropical anticyclone to the north of the convection (SFI; e.g., Matsuno 1966; Gill 1980) and also affects the strength and position of the eastern Pacific ridge (PVDI; e.g., Barriopedro et al. 2006; Moore et al. 2010). Hence, active tropical convection, a strengthened subtropical anticyclone, and a pronounced downstream (a)

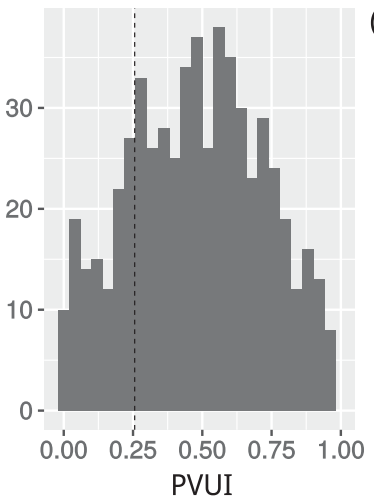

(e)

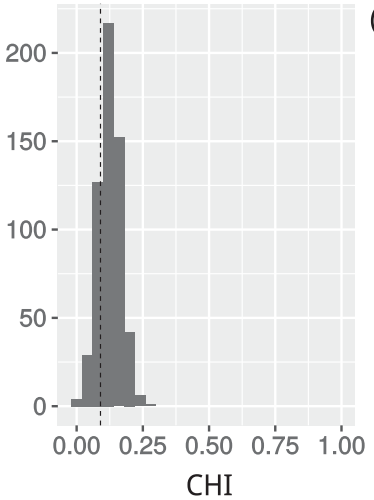

(b) 40

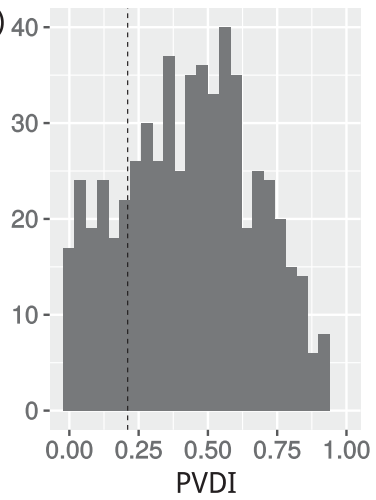

(f)

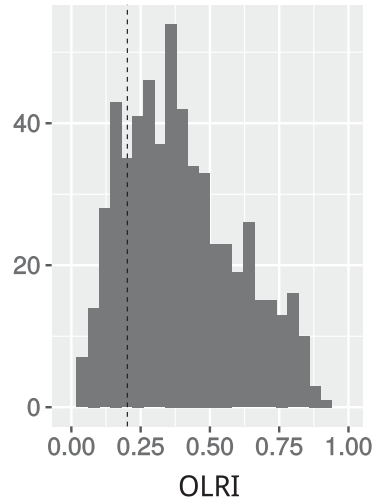

(c)

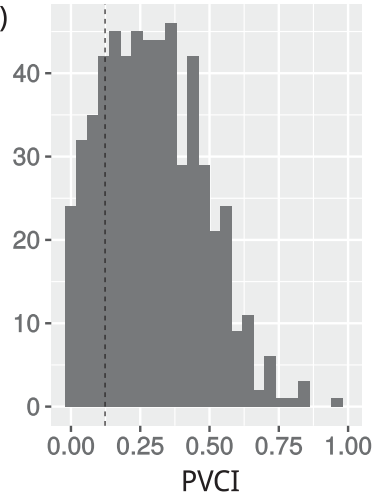

(g) 1

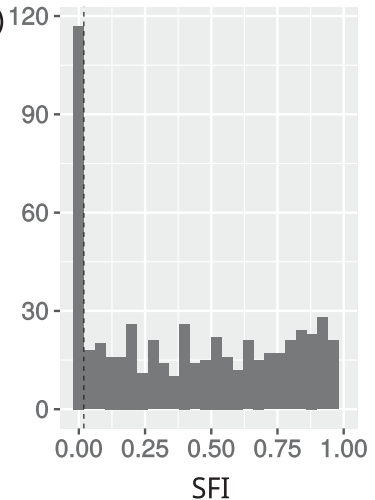

(d)

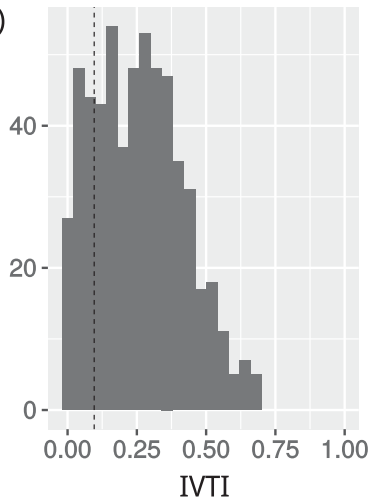

(h)

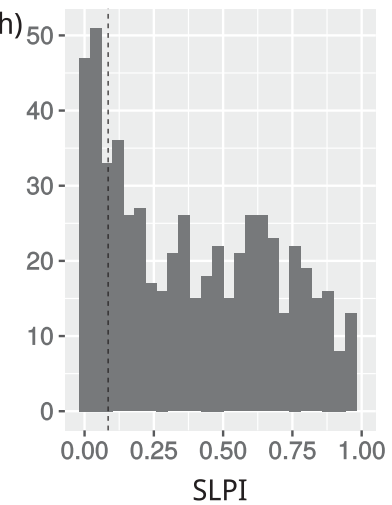

FIG. 10. Histograms of the feature indices for North Pacific RWI events in DJF. The vertical dashed line depicts the 20th percentile of the respective distribution. 
TABLE 2. Total Spearman rank correlation matrix. Statistical significance was assessed with the standard Student's $t$ test and statistically significant correlations at $\alpha=0.01$ are indicated with an asterisk.

\begin{tabular}{lccccccc}
\hline & PVDI & PVCI & SFI & OLRI & SLPI & IVTI & CHI \\
\hline PVUI & -0.08 & $0.16^{*}$ & $-0.22^{*}$ & $-0.12^{*}$ & $0.37^{*}$ & $0.34^{*}$ & $0.27^{*}$ \\
PVDI & - & $0.15^{*}$ & $0.28^{*}$ & $0.25^{*}$ & 0.01 & 0.03 & -0.04 \\
PVCI & - & - & $-0.11^{*}$ & -0.02 & 0.01 & 0.00 & 0.04 \\
SFI & - & - & - & $0.38^{*}$ & 0.09 & 0.09 & $0.14^{*}$ \\
OLRI & - & - & - & - & -0.03 & -0.02 & 0.02 \\
SLPI & - & - & - & - & - & $0.74^{*}$ & $0.37^{*}$ \\
IVTI & - & - & - & - & - & - & $0.49^{*}$ \\
\hline
\end{tabular}

ridge also tend to co-occur. Further, these indices are uncorrelated with SLPI, CHI, and IVTI and weakly anticorrelated with PVUI. The partial correlations shown in Table 3 reveal that this anticorrelation is primarily due to an anticorrelation between PVUI and SFI, as there are no significant partial anticorrelations between PVUI and PVDI as well as OLRI. Therefore, if a particularly pronounced upstream PV anomaly is present during an individual RWI event, the subtropical anticyclone in the SFI box tends to be weaker and vice versa. However, apart from PVUI and SFI, the indices are either positively correlated or uncorrelated (Table 3). Therefore, the features are generally not mutually exclusive. This is an important result as it shows that even though there are preferred combinations of features, which might be regarded as idealized archetypal RWI scenarios, other combinations also occur during individual RWI events. Therefore, the RWI events do not cluster in the PC1-PC2 plane (Fig. 11).

\section{RWI in summer over the Tibetan Plateau}

Next, we briefly compare the composites for DJF North Pacific RWI events with those for RWI events in the most active RWI region in summer, which is located between the Tibetan Plateau and the western North Pacific (Fig. 3). RWI events occurring in segments starting between $30^{\circ}$ and $120^{\circ} \mathrm{E}$ in summer are further referred to as JJA Tibetan Plateau RWI events (see also Fig. S1b). Many of these RWI events occur north of the Himalayas and, hence, in a drier region with strongly elevated topography compared to the North Pacific in winter. Despite this, time-lagged composites of JJA Tibetan Plateau RWI events show qualitatively similar but weaker signals for upper-level quantities compared to the composites for DJF North Pacific RWI events (Figs. 5, 6, and 12). The JJA Tibetan Plateau composites also show a positive PV anomaly upstream of the RWI segment prior to initiation (Fig. 12a). Moreover, the SF anomalies also reveal a deformation flow pattern during
TABLE 3. Partial Spearman rank correlation matrix. Statistical significance was assessed with the standard Student's $t$ test with $N-2-g$ degrees of freedom, where $N$ is the number of RWI events considered, and $g$ is the number of controlled variables. Statistically significant partial correlations at $\alpha=0.01$ are indicated with an asterisk. The R package ppcor (Kim 2015) was used to calculate partial correlations as well as to perform the significance testing.

\begin{tabular}{lccccccc}
\hline & PVDI & PVCI & \multicolumn{1}{c}{ SFI } & OLRI & SLPI & IVTI & CHI \\
\hline PVUI & -0.02 & $0.14^{*}$ & $-0.25^{*}$ & -0.01 & $0.20^{*}$ & 0.06 & $0.16^{*}$ \\
PVDI & - & $0.20^{*}$ & $0.23^{*}$ & $0.16^{*}$ & -0.01 & 0.06 & -0.10 \\
PVCI & - & - & $-0.12^{*}$ & -0.01 & 0.00 & -0.05 & 0.05 \\
SFI & - & - & - & $0.31^{*}$ & 0.10 & 0.00 & $0.16^{*}$ \\
OLRI & - & - & - & - & -0.03 & -0.01 & 0.01 \\
SLPI & - & - & - & - & - & $0.66^{*}$ & -0.03 \\
IVTI & - & - & - & - & - & - & $0.34^{*}$ \\
\hline
\end{tabular}

and after RWI (Figs. 12b-d), as well as ridge building in the downstream half of the initiation segment after the time of RWI (Figs. 12c,d). However, only a very weak negative SLP anomaly $(-2 \mathrm{hPa})$ is apparent at the time of initiation (Fig. 12b), which weakens thereafter. Furthermore, no coherent and statistically significant anomalies in tropical OLR, IVT, $\mathrm{CH}$, and WCB features are found (not shown).

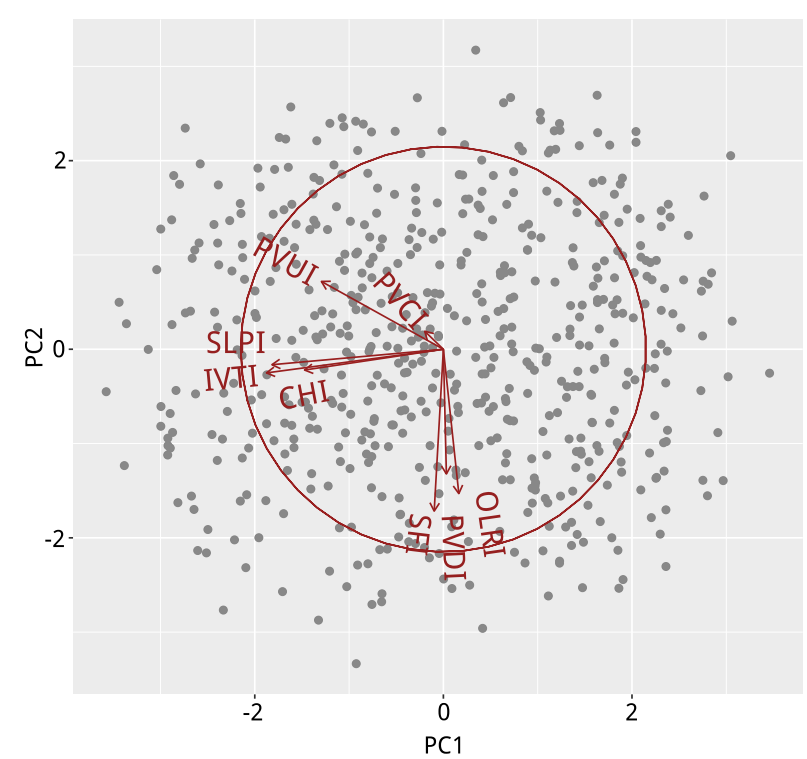

FIG. 11. DJF North Pacific RWI events projected onto the PC1PC2 plane (gray dots). The feature indices are depicted as red arrows, which are defined by their correlations with the first two PCs and have been scaled for visibility reasons (i.e., there are two coordinate systems superimposed in this figure). The unit circle for the correlations is indicated in red. Long arrows indicate indices that contribute strongly to the first two PCs. Arrows pointing in similar (opposite) directions indicate positively correlated (anticorrelated) indices, while arrows at right angles indicate uncorrelated indices. 


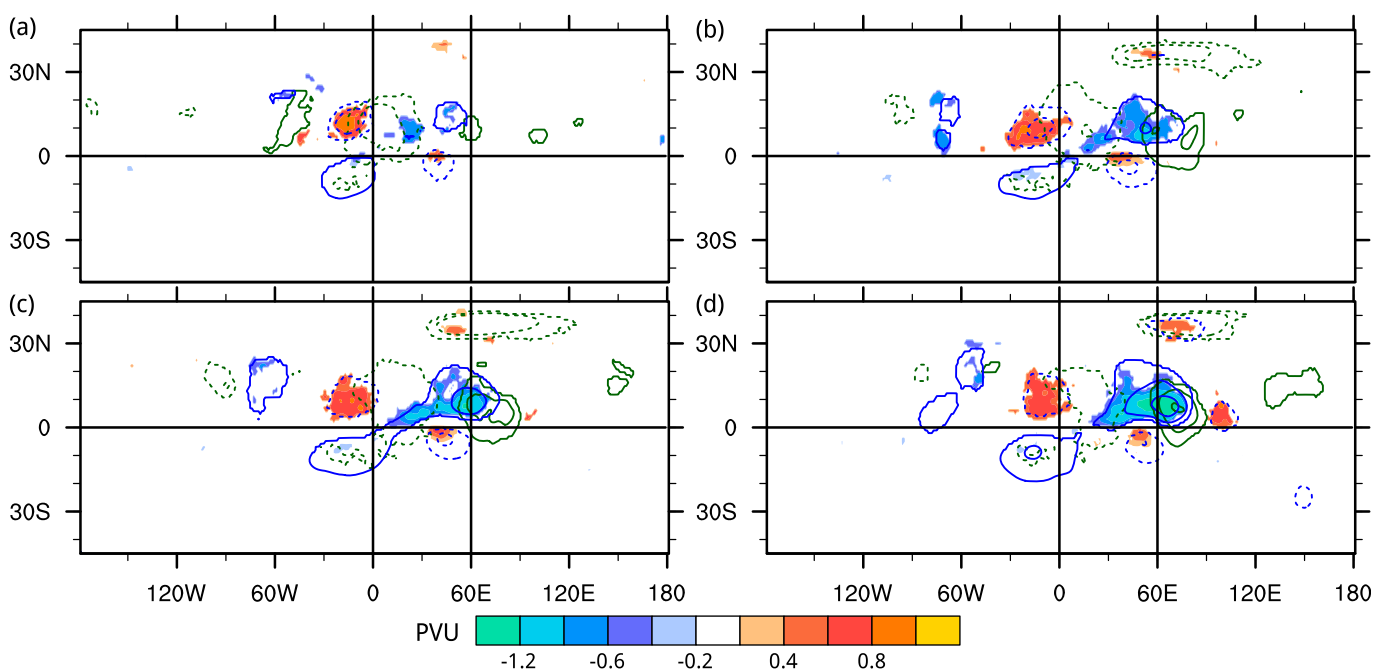

FIG. 12. Time-lagged PV anomaly composites for JJA Tibetan Plateau RWI events for lags (a) -48 , (b) 0 , (c) +12 , and (d) $+36 \mathrm{~h}$ (shading). Green solid and dashed contours depict positive and negative SLP anomalies, respectively, of \pm 1 and $\pm 2 \mathrm{hPa}$. Blue solid and dashed contours depict positive and negative anomalies of $250-\mathrm{hPa}$ streamfunction, respectively, of $\pm 2, \pm 4$, and $\pm 6 \times 10^{6} \mathrm{~m}^{2} \mathrm{~s}^{-1}$. Only statistically significant anomalies are shown.

The JJA Himalayan composites thus corroborate the importance of a positive upstream PV anomaly as well as large-scale deformation for RWI. The lack of pronounced signals in SLP and moisture-related quantities (IVT, $\mathrm{CH}$, and WCB frequencies) conceivably result from the elevated topography of the Tibetan Plateau, which reduces the column-integrated moisture and adversely affects the computation of SLP (i.e., cyclones cannot be meaningfully identified from SLP in this region).

\section{Summary and conclusions}

In this study we compiled the first all-season climatology of Northern Hemisphere RWI on the extratropical jet. We have used the RWI identification method introduced by Röthlisberger et al. (2016) and identified 2577 RWI events between January 1979 and March 2016. The number of RWI events per month exhibits a seasonal cycle with RWI events occurring most frequently in winter with a median of nine RWI events in January. The frequency of RWI events covaries with how often the extratropical jet is zonal, as following our definition waves can be initiated only in zonal jet segments.

The spatial distribution of RWI events on the extratropical jet in winter shows two distinct peak regions, located over the North Pacific and the North Atlantic, respectively. The North Pacific RWI region shifts toward the Tibetan Plateau in summer. Over the North Atlantic, fewer RWI events occur during spring and fall than during winter and summer. Moreover, RWI events tend to occur at the downstream end of the strongest climatological jets and baroclinic zones, in the regions of the climatologically strongest condensational heating.

By performing a composite analysis of RWI events occurring over the North Pacific in winter we identify several features that exist prior to RWI: an upstream wave train propagating across Asia on the Arctic waveguide, enhanced moisture transport along and toward the zonal jet, a ridge downstream of the initiation segment and active tropical convection, and a strengthened subtropical anticyclone just west of the initiation segment.

The forming composite wave exhibits a baroclinic structure and develops downstream of a southwestnortheast-tilted positive PV anomaly, which is part of the upstream wave train on the poleward side of the jet. Such a flow configuration is expected for waves initiated either by TPVs or by anticyclonically breaking waves on the Arctic waveguide. Also, at the time of initiation, strong latent heat release in the ascending WCB intensifies the forming cyclone (e.g., Binder et al. 2016) and leads to upper-level ridge building within the initiation segment. The WCB activity and upper-level ridge building cease about $48 \mathrm{~h}$ after RWI and downstream development of the new wave packet is evident at this time. Earlier studies illustrated RWI due to TPVs, breaking waves, and WCBs in extratropical cyclones on a case study basis (Kew et al. 2010; Martius et al. 2010; Grams et al. 2011; Röthlisberger et al. 2016). This study now also provides compelling evidence for the climatological relevance of these mechanisms for RWI.

A novel result is that synoptic-scale Rossby waves tend to form upstream of a preexisting ridge. The 

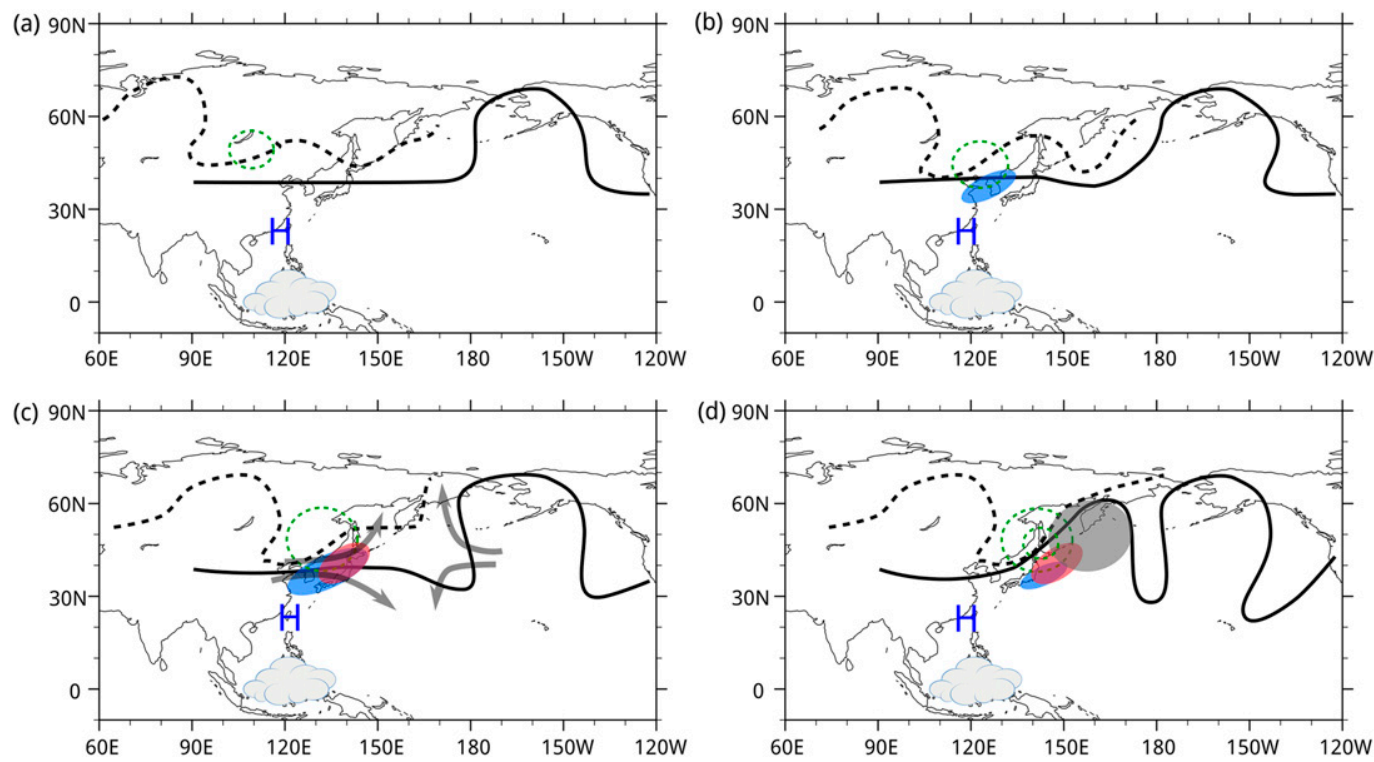

FIG. 13. Schematic evolution of a DJF North Pacific RWI event for lags of approximately (a) from -72 to $-42 \mathrm{~h}$, (b) from -36 to $-12 \mathrm{~h}$, (c) from -6 to $+6 \mathrm{~h}$, and (d) from +12 to $+48 \mathrm{~h}$. The solid (dashed) black line depicts the 2-PVU contour on the $320-\mathrm{K}(310 \mathrm{~K})$ isentropic surface. Green dashed contours indicate the forming cyclone. Blue, red, and gray shading depicts WCB inflow, ascent, and outflow, respectively. Active tropical convection and the strengthened subtropical anticyclone are indicated with a cloud symbol and the letter $\mathrm{H}$, respectively. The gray arrows in (c) indicate the different contributions to the deformation flow field.

presence of this ridge, in combination with the upstream PV anomaly and the strengthened subtropical anticyclone, induces large-scale upper-level deformation, which supports the meridional amplification of the forming wave and is further associated with increased (decreased) jet speed upstream of (within) the RWI segment compared to random zonal jet segments. The effect of large-scale upper-level deformation on the development and shape of synoptic-scale waves was previously discussed in the context of atmospheric blocking (e.g., Berggren et al. 1949; Shutts 1983). However, its more general relevance for the initiation and growth of synoptic-scale waves is a novel finding of this study.

In summary, the composite analysis of DJF Pacific RWI events reveals the following four extratropical key ingredients of RWI: 1) a stratospheric positive PV anomaly to the north of the jet upstream of the initiation segment, 2) latent heating and subsequent formation of a negative PV anomaly on the southern side of the jet (i.e., ridge building) within the initiation segment, 3) baroclinic growth, and 4) large-scale upper-level deformation. Moreover, stationary anomalies in tropical convection precede RWI by more than 20 days and point to the role of active tropical convection in geographically anchoring RWI events.

To draw inferences on the occurrence and cooccurrence of these composite features during individual RWI events, indices were defined that measure the amplitude of one particular composite feature during individual RWI events. The indices reveal that some features, such as the upstream PV anomaly or increased condensational heating, occur in almost all RWI events in the same region as in the composites, albeit with strongly variable spatial extent. Others, such as the strengthened subtropical anticyclone, can be lacking entirely or are displaced compared to the composite feature during some RWI events.

Further, indices that are physically related to the forming cyclone (upstream PV anomaly, negative SLP anomaly, and positive IVT and $\mathrm{CH}$ anomalies) are positively correlated. This implies that during individual RWI events a strong surface cyclone tends to co-occur with strong latent heating, moisture transport, and a pronounced positive PV anomaly aloft, and analogously for weak cyclones. A second group of (weakly) correlated indices, which is independent of the first, contains indices for active tropical convection, the strengthened subtropical anticyclone, and the downstream ridge. Moreover, only the indices for the upstream PV and streamfunction anomalies are anticorrelated and thus represent mutually exclusive features. For the remaining indices the correlations are either positive or close to zero, which implies that features from both groups often also occur together.

The conclusions drawn from this analysis are limited by the fact that for individual RWI events there is not 
necessarily a causal link between the occurrence of a particular feature and RWI. Therefore, we cannot directly infer from this analysis which of the four ingredients is dynamically the most dominant for a particular RWI event. Nevertheless, the indices are calculated for more than 500 RWI events and show that in most events several of the composite features are present. Therefore, even though not all features must be relevant in each RWI event, it appears that often a combination of mechanisms operates in concert to induce RWI. This seems plausible: if the individual key ingredients are each conducive to RWI, their combination should be even more so and is thus the preferred way how RWI occurs.

In summary, the results of this study promote the following schematic view of (DJF Pacific) RWI (Fig. 13): A strengthened subtropical anticyclone developing to the north of active tropical convection facilitates the formation of a zonal and straight jet stream over the North Pacific (Fig. 13a). Over eastern Asia, breaking waves on the Arctic waveguide and TPVs moving south occur frequently and can act as positive PV anomalies north of the zonal extratropical jet. Once such a positive PV anomaly is sufficiently close to the zonal jet it starts to perturb the latter via its far-field effect and induces ridge building downstream of the PV anomaly. Moreover, its interaction with the low-level baroclinicity and moisture leads to cyclone formation and intensification (Figs. 13b,c). In the forming cyclone a WCB develops, and its outflow impinges on the jet and intensifies the upper-level ridge (Fig. 13d). Furthermore, the forming wave is amplified meridionally by a large-scale upper-level deformation flow field induced by the upstream PV anomaly (i.e., breaking wave or TPV), the strengthened subtropical anticyclone, and the downstream ridge (Fig. 13c). Later on, the wave energy is dispersed downstream along the North Pacific waveguide (Fig. 13d).

Acknowledgments. The authors are grateful to Dr. Michael Sprenger (ETH Zürich) for technical support as well as two anonymous reviewers for their encouraging and thoughtful reviews. This research was funded by the Swiss National Science Foundation (Grant 200021_ 159905/1).

\section{REFERENCES}

Archambault, H. M., L. F. Bosart, D. Keyser, and J. M. Cordeira, 2013: A climatological analysis of the extratropical flow response to recurving western North Pacific tropical cyclones. Mon. Wea. Rev., 141, 2325-2346, https://doi.org/10.1175/ MWR-D-12-00257.1.

Barriopedro, D., R. García-Herrera, A. R. Lupo, and E. Hernández, 2006: A climatology of Northern Hemisphere blocking. J. Climate, 19, 1042-1063, https://doi.org/10.1175/ JCLI3678.1.
Benjamini, Y., and Y. Hochberg, 1995: Controlling the false discovery rate: A practical and powerful approach to multiple testing. J. Roy. Stat. Soc., 57B, 289-300.

Berggren, R., B. Bolin, and C.-G. Rossby, 1949: An aerological study of zonal motion, its perturbations and break-down. Tellus, 1 (2), 14-37, https://doi.org/10.3402/tellusa.v1i2.8501.

Binder, H., M. Boettcher, H. Joos, and H. Wernli, 2016: The role of warm conveyor belts for the intensification of extratropical cyclones in Northern Hemisphere winter. J. Atmos. Sci., 73, 3997-4020, https://doi.org/10.1175/JAS-D-15-0302.1.

Cavallo, S. M., and G. J. Hakim, 2009: Potential vorticity diagnosis of a tropopause polar cyclone. Mon. Wea. Rev., 137, 13581371, https://doi.org/10.1175/2008MWR2670.1.

Chang, E. K. M., 1993: Downstream development of baroclinic waves as inferred from regression analysis. J. Atmos. Sci., 50, 2038-2053, https://doi.org/10.1175/1520-0469(1993)050<2038: DDOBWA $>2.0 . \mathrm{CO} ; 2$.

, and D. B. Yu, 1999: Characteristics of wave packets in the upper troposphere. Part I: Northern Hemisphere winter. J. Atmos. Sci., 56, 1708-1728, https://doi.org/10.1175/1520-0469(1999)056<1708: COWPIT $>2.0 . \mathrm{CO} ; 2$.

Davies, H. C., and M. Didone, 2013: Diagnosis and dynamics of forecast error growth. Mon. Wea. Rev., 141, 2483-2501, https:// doi.org/10.1175/MWR-D-12-00242.1.

Dee, D. P., and Coauthors, 2011: The ERA-Interim reanalysis: Configuration and performance of the data assimilation system. Quart. J. Roy. Meteor. Soc., 137, 553-597, https://doi.org/10.1002/qj.828.

Froidevaux, P., and O. Martius, 2016: Exceptional integrated vapour transport toward orography: An important precursor to severe floods in Switzerland. Quart. J. Roy. Meteor. Soc., 142, 1997-2012, https://doi.org/10.1002/qj.2793.

Gill, A. E., 1980: Some simple solutions for heat-induced tropical circulation. Quart. J. Roy. Meteor. Soc., 106, 447-462, https:// doi.org/10.1002/qj.49710644905.

Glatt, I., and V. Wirth, 2014: Identifying Rossby wave trains and quantifying their properties. Quart. J. Roy. Meteor. Soc., 140, 384-396, https://doi.org/10.1002/qj.2139.

Graf, M. A., H. Wernli, and M. Sprenger, 2017: Objective classification of extratropical cyclogenesis. Quart. J. Roy. Meteor. Soc., 143, 1047-1061, https://doi.org/10.1002/qj.2989.

Grams, C. M., and H. M. Archambault, 2016: The key role of diabatic outflow in amplifying the midlatitude flow: A representative case study of weather systems surrounding western North Pacific extratropical transition. Mon. Wea. Rev., 144, 3847-3869, https://doi.org/10.1175/MWR-D-15-0419.1.

_ , and Coauthors, 2011: The key role of diabatic processes in modifying the upper-tropospheric wave guide: A North Atlantic case-study. Quart. J. Roy. Meteor. Soc., 137, 2174-2193, https://doi.org/10.1002/qj.891.

Grazzini, F., and F. Vitart, 2015: Atmospheric predictability and Rossby wave packets. Quart. J. Roy. Meteor. Soc., 141, $2793-$ 2802, https://doi.org/10.1002/qj.2564.

Hakim, G. J., 2003: Developing wave packets in the North Pacific storm track. Mon. Wea. Rev., 131, 2824-2837, https://doi.org/ 10.1175/1520-0493(2003)131<2824:DWPITN>2.0.CO;2.

Heifetz, E., C. H. Bishop, B. J. Hoskins, and J. Methven, 2004: The counter-propagating Rossby-wave perspective on baroclinic instability. I: Mathematical basis. Quart. J. Roy. Meteor. Soc., 130, 211-231, https://doi.org/10.1002/qj.200413059610.

Hoskins, B. J., and T. Ambrizzi, 1993: Rossby wave propagation on a realistic longitudinally varying flow. J. Atmos. Sci., 50, 1661-1671, https://doi.org/10.1175/1520-0469(1993)050<1661: RWPOAR $>2.0 . \mathrm{CO} ; 2$. 
— M. E. McIntyre, and A. W. Robertson, 1985: On the use and significance of isentropic potential vorticity maps. Quart. J. Roy. Meteor. Soc., 111, 877-946, https://doi.org/10.1002/ qj. 49711147002.

Jolliffe, I. T., 2002: Principal Component Analysis. 2nd ed. Springer, $487 \mathrm{pp}$.

Kew, S. F., M. Sprenger, and H. C. Davies, 2010: Potential vorticity anomalies of the lowermost stratosphere: A 10-yr winter climatology. Mon. Wea. Rev., 138, 1234-1249, https://doi.org/ 10.1175/2009MWR3193.1.

Kim, S., 2015: ppcor: An R package for a fast calculation to semipartial correlation coefficients. Commun. Stat. Appl. Methods, 22, 665-674, https://doi.org/10.5351/CSAM.2015.22.6.665.

Lee, S., and I. M. Held, 1993: Baroclinic wave packets in models and observations. J. Atmos. Sci., 50, 1413-1428, https://doi.org/ 10.1175/1520-0469(1993)050<1413:BWPIMA > 2.0.CO;2.

Liebmann, B., and C. A. Smith, 1996: Description of a complete (interpolated) outgoing longwave radiation dataset. Bull. Amer. Meteor. Soc., 77, 1275-1277.

Madonna, E., H. Wernli, H. Joos, and O. Martius, 2014: Warm conveyor belts in the ERA-Interim dataset (1979-2010). Part I: Climatology and potential vorticity evolution. J. Climate, 27, 3 26, https://doi.org/10.1175/JCLI-D-12-00720.1.

Martínez-Alvarado, O., E. Madonna, S. L. Gray, and H. Joos, 2016: A route to systematic error in forecasts of Rossby waves. Quart. J. Roy. Meteor. Soc., 142, 196-210, https://doi.org/10.1002/qj.2645.

Martius, O., C. Schwierz, and H. C. Davies, 2006: A refined Hovmöller diagram. Tellus, 58A, 221-226, https://doi.org/10.1111/ j.1600-0870.2006.00172.x.

, - $\longrightarrow$, and - 2010: Tropopause-level waveguides. J. Atmos. Sci., 67, 866-879, https://doi.org/10.1175/2009JAS2995.1.

Matsuno, T., 1966: Quasi-geostrophic motions in the equatorial area. J. Meteor. Soc. Japan, 44, 25-43, https://doi.org/10.2151/ jmsj1965.44.1_25.

Methven, J., 2015: Potential vorticity in warm conveyor belt outflow. Quart. J. Roy. Meteor. Soc., 141, 1065-1071, https:// doi.org/10.1002/qj.2393.

Moore, R. W., O. Martius, and T. Spengler, 2010: The modulation of the subtropical and extratropical atmosphere in the Pacific basin in response to the Madden-Julian oscillation. Mon. Wea. Rev., 138, 2761-2779, https://doi.org/10.1175/2010MWR3194.1.

Riemer, M., S. C. Jones, and C. A. Davis, 2008: The impact of extratropical transition on the downstream flow: An idealized modelling study with a straight jet. Quart. J. Roy. Meteor. Soc., 134, 69-91, https://doi.org/10.1002/qj.189.

Rodwell, M. J., and Coauthors, 2013: Characteristics of occasional poor medium-range weather forecasts for Europe. Bull. Amer. Meteor. Soc., 94, 1393-1405, https://doi.org/ 10.1175/BAMS-D-12-00099.1.
Röthlisberger, M., O. Martius, and H. Wernli, 2016: An algorithm for identifying the initiation of synoptic-scale Rossby waves on potential vorticity waveguides. Quart. J. Roy. Meteor. Soc., 142, 889-900, https://doi.org/10.1002/qj.2690.

Schiemann, R., D. Lüthi, and C. Schär, 2009: Seasonality and interannual variability of the westerly jet in the Tibetan Plateau region. J. Climate, 22, 2940-2957, https://doi.org/10.1175/ 2008JCLI2625.1.

Schwierz, C., S. Dirren, and H. C. Davies, 2004: Forced waves on a zonally aligned jet stream. J. Atmos. Sci., 61, 73-87, https://doi.org/ 10.1175/1520-0469(2004)061<0073:FWOAZA > 2.0.CO;2.

Shutts, G. J., 1983: The propagation of eddies in diffluent jetstreams: Eddy vorticity forcing of 'blocking' flow fields. Quart. J. Roy. Meteor. Soc., 109, 737-761, https://doi.org/10.1002/ qj.49710946204.

Souders, M. B., B. A. Colle, and E. K. M. Chang, 2014: The climatology and characteristics of Rossby wave packets using a feature-based tracking technique. Mon. Wea. Rev., 142, 35283548, https://doi.org/10.1175/MWR-D-13-00371.1.

Sprenger, M., and Coauthors, 2017: Global climatologies of Eulerian and Lagrangian flow features based on ERA-Interim. Bull. Amer. Meteor. Soc., 98, 1739-1748, https://doi.org/ 10.1175/BAMS-D-15-00299.1.

Stensrud, D. J., 2013: Upscale effects of deep convection during the North American monsoon. J. Atmos. Sci., 70, 2681-2695, https://doi.org/10.1175/JAS-D-13-063.1.

Teubler, F., and M. Riemer, 2016: Dynamics of Rossby wave packets in a quantitative potential vorticity-potential temperature framework. J. Atmos. Sci., 73, 1063-1081, https:// doi.org/10.1175/JAS-D-15-0162.1.

Torn, R. D., and G. J. Hakim, 2015: Comparison of wave packets associated with extratropical transition and winter cyclones. Mon. Wea. Rev., 143, 1782-1803, https://doi.org/10.1175/ MWR-D-14-00006.1.

Ventura, V., C. J. Paciorek, and J. S. Risbey, 2004: Controlling the proportion of falsely rejected hypotheses when conducting multiple tests with climatological data. J. Climate, 17, 43434356, https://doi.org/10.1175/3199.1.

Wernli, H., and H. C. Davies, 1997: A Lagrangian-based analysis of extratropical cyclones. I: The method and some applications. Quart. J. Roy. Meteor. Soc., 123, 467-489, https://doi.org/ 10.1002/qj.49712353811.

Wilks, D. S., 2011: Statistical Methods in the Atmospheric Sciences. 3rd ed. International Geophysics Series, Vol. 100, Elsevier, 704 pp.

, 2016: "The stippling shows statistically significant grid points": How research results are routinely overstated and overinterpreted, and what to do about it. Bull. Amer. Meteor. Soc., 97, 2263-2274, https://doi.org/10.1175/BAMS-D-15-00267.1. 